\title{
Theoretical Research and Numerical Simulation on Water Resistance Mechanism of Textile Bag in Water Passage
}

\author{
Ang Li $\mathbb{D}^{1},{ }^{1}$ Yuxuan Yang $\mathbb{D}^{1},{ }^{1}$ Mingcheng Zhu $\mathbb{D}^{2},{ }^{2}$ Wenzhong Zhang $\mathbb{D}^{2},{ }^{2}$ Bingnan Ji $\mathbb{D}^{1}$ \\ and Xuesong Ding iD 1 \\ ${ }^{1}$ Xi'an University of Science and Technology, Xi'an 710054, China \\ ${ }^{2}$ Xi'an Research Institute of China Coal Technology \& Engineering Group Corp, Xi'an, 710054 Shaanxi, China \\ Correspondence should be addressed to Ang Li; ang.li3399@gmail.com
}

Received 26 January 2021; Revised 11 February 2021; Accepted 22 February 2021; Published 8 March 2021

Academic Editor: Bin Gong

Copyright ( $) 2021$ Ang Li et al. This is an open access article distributed under the Creative Commons Attribution License, which permits unrestricted use, distribution, and reproduction in any medium, provided the original work is properly cited.

\begin{abstract}
It is an important problem in the mine water disaster prevention and control to control the large passage moving water. Traditional grouting technology is to put coarse aggregate and fine aggregate downward first and then grouting treatment. But the aggregate and cement flow distance is long, consumption is large, cost is high, and easy to appear secondary water inrush. Centering on the technical difficulties in the rapid construction of the blocking body of the moving water passage, a water-blocking textile bag was invented. The purpose of blocking the tunnel water inrush was achieved by grouting inside the bag body, which fundamentally realized the rapid blocking of the large passage through water under the condition of moving water. However, the mechanism, water plugging law, and design parameters of water blocking roadway with textile bag are still unclear. In this paper, the slip law and stability of the textile bag in the moving water and the deformation characteristics caused by the dynamic water pressure are theoretically analyzed and simulated. Through theoretical analysis, the ultimate antihydraulic stress value of a textile bag of a certain specification is calculated, and the parameters of the textile bag that affect the stability of the bag body are also determined. Xflow was used for numerical simulation analysis to study the deformation characteristics of the textile bag under water and the law of water barrier. The simulation analysis focuses on the water resistance effect and flow field distribution characteristics of the textile bag in the water passage under the condition of low flow rate and low pressure, as well as the stability and self-deformation characteristics of the textile bag under the condition of high flow rate and high pressure. The accuracy of the limit resistance to water pressure of the textile bag obtained from theoretical analysis is verified. The results show that the theoretical analysis is consistent with the simulation results. The textile bag can realize the fast controllable plugging of the large water passage of moving water within the limit of the antihydraulic stress.
\end{abstract}

\section{Introduction}

Mine water disaster is one of the five natural disasters affecting coal mine safety production. Flooded well and extremely large flooding accidents occur frequently. Every year, China's coal mines will lose huge human and financial resources due to water disaster $[1,2]$. In order to effectively control the threat of water damage to China's mines, the Detailed rules for Coal Mine Water Prevention and Control have formulated a number of comprehensive water damage control measures. Grouting water plugging technology has become the most important treatment means for most of the present water damage mines [3-7].

The grouting work is usually carried out under the condition of moving water. Conventional grouting technology is to fill aggregate and auxiliary materials first and then replenish grouting [8] because aggregate and slurry cannot be stable accumulation and diffusion in the initial stage. Therefore, problems such as long treatment period, large amount of grouting and supporting works, easy to be repeated in the treatment process, and high cost and long time of follow-up reprocessing will occur, aiming at the characteristics of water 
inrush with large flow, larger than water channel and clear channel location, and considering the practical needs of time urgency. The blocking water technology is adopted, in which the textile bag is first placed at the designated point and then the grouting is supplemented or the grouting is supplemented after the proper amount of aggregate is poured in the later stage $[9,10]$. It can quickly reduce the water cross section of roadway, reduce the water flow, effectively control the diffusion scope of slurry injection, reduce the amount of rescue work and time limit, and reduce the cost and time of the follow-up recovery of mining. And its special construction technology can also reduce or eliminate secondary hazards.

The water plugging technology of the water passage grouting has been successfully applied in the water disaster control work of every large coal mine in China. But at present, the research on the dynamic water grouting mainly focuses on the grouting technology and the grouting material [11-17]. And the research on the water barrier mechanism of the moving water of the water passage is very few. Xu et al. used the Matlab simulation software to carry out dynamic numerical simulation of the sealing process of water inrush channel and determined the minimum particle size of the aggregate added in the grouting process [18]. At the same time, the process of grouting is simulated to master the change of hydrodynamic conditions in the process of grouting, so as to provide certain theoretical guidance for the smooth development of water plugging work. Based on the construction example of a deep reinforced concrete water seal in a coal mine in China, $\mathrm{Li}$ et al. used the 3D numerical model of the structure developed by FLAC3D to study the stress and displacement distribution and plastic zone range of the rock around the water seal structure [19]. By means of theoretical analysis, laboratory tests, and engineering projects, Wang et al. deeply studied the mechanism of slurry diffusion and blockage in dynamic water grouting [20]. Aiming at the shortage of hydrodynamic grouting materials at present, Wang et al. systematically analyzed the preparation, properties, and reinforcement mechanism of the new grouting materials by means of theoretical analysis, laboratory test, field test, and microscopic research [21]. Based on numerical mechanics model (CFD-DEM), Mou et al. studied the aggregate perfusion process and the water closure mechanism [22].

Previous studies have shown that few studies on the mechanism of hydrodynamic water barrier in water passage focus only on the conventional hydrodynamic water barrier methods. Moreover, only single numerical simulation, small single physical simulation of aggregate perfusion, and single theoretical analysis were conducted. There are few researches on water barrier mechanism of grouting with textile bag. Due to the strong concealment of underground engineering construction, it is impossible to directly observe the process of grouting plugging on site, and it is also impossible to conduct anatomical verification on the grouting plugging body in the later stage. Therefore, it is necessary to study the mechanism of rapid water blocking by moving water in water passage. In this paper, theoretical analysis and numerical simulation are combined to conduct a comprehensive study on the process of textile bag blocking the water passage.

\section{Theoretical Analysis of Textile Bag under the Action of Hydraulic Load}

2.1. Shear Slip Model. A three-stage linear function is used to describe the relationship between shear stress and shear displacement on the contact surface between textile bag and roadway surrounding rock. Stage I corresponds to the elastic stage, and the shear stress and shear displacement of the contact surface is proportional to the change. At this stage, the contact surface is in a lossless state. Stage II corresponds to the contact surface of the softening damage stage, and modulus reduction is used to describe the nature of the shear stress on the contact surface decreases with the increase of shear displacement. Stage III corresponds to the residual strength on the surface of the contact, the contact surface in a fully damage state, only the frictional resistance.

The shear stress and displacement relationship of the corresponding three-stage linear model is shown in Figure 1, which can be expressed by the formula as follows:

$$
\tau=K u+\xi,
$$

where $\tau$ is the shear stress, $u$ is shear displacement, $K$ and $\xi$ are material parameters that can be determined by test.

The relationship between shear stress and displacement corresponding to different stages can be expressed as follows:

(1) $0 \leq u \leq u_{1}$ :

$$
K=K_{1}=\frac{\tau_{1}}{u_{1}}, \xi=0 .
$$

(2) $u_{1} \leq u \leq u_{2}$ :

$$
K=K_{2}=\frac{\tau_{1}-\tau_{2}}{u_{1}-u_{2}}, \xi=\frac{\tau_{2} u_{1}-\tau_{1} u_{2}}{u_{1}-u_{2}} .
$$

(3) $u \geq u_{2}$ :

$$
K=K_{3}=0, \xi=\tau_{2} .
$$

2.2. Mechanical Equilibrium Analysis of the Textile Bag Microelement. The textile bag is subjected to the action of hydraulic stress $\sigma_{P}$, and the pressure is transmitted to the stratum through the surrounding rock friction around the textile bag. When the shear stress of the contact surface between the textile bag and the roadway is less than the shear strength of the interface, the interface is in a state of complete elasticity. There is no relative displacement, and the relation of deformation and coordination is satisfied between them. Once the shear stress on the interface between the textile bag and the roadway exceeds the shear strength of the interface, the interface will slip and enter the stage of plastic softening. With the further increase of the load, the beginning end of the textile bag will enter the residual shear stage.

In theoretical calculation, the textile bag is regarded as a regular prism that does not contact with the top of the tunnel. 


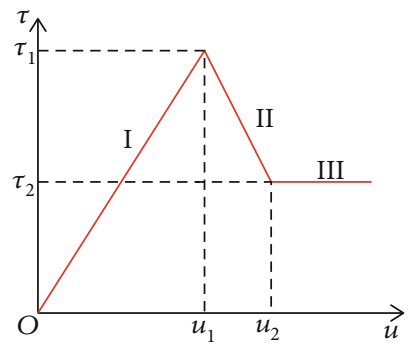

FIGURE 1: Relationship between shear stress and shear displacement of surrounding rock.

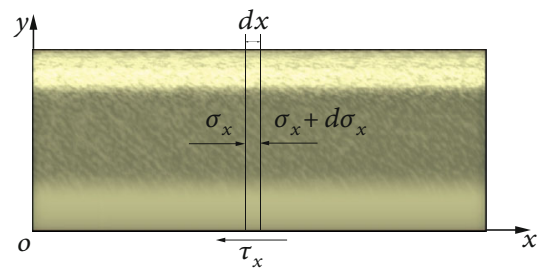

FIgURE 2: Static equilibrium model of textile bag.

The water inlet end is on the left side, and on the right is the water outlet end assuming that the water pressure is 0 . Let the length, width, and height of the textile bag be $l, b$, and $h$, respectively. The modulus of elasticity is $E$. The lateral resistance on the roadway is $\tau(u)$, which is a function of shear displacement $u$. Assuming that the material of textile bag conforms to Hooke's law, a microsection is taken at the length of textile bag $x$ and its length is $d x$, as shown in Figure 2, considering the relationship between strain and stress and the static equilibrium of textile bag microsection.

$$
\sigma_{x} h b-\left(\sigma_{x}+d \sigma_{x}\right) h b-\tau_{x}(2 h+b) d x=0 .
$$

From (4),

$$
\frac{d \sigma_{x}}{d x}=-\frac{2 h+b}{h b} \tau_{x}
$$

Assuming that the textile bag maintains linear elasticity throughout the experiment, the equation for the interface and textile bag is as follows:

$$
-\sigma_{x}=E \frac{d u(x)}{d x}
$$

Shear slip is defined as the relative displacement between textile bag and surrounding rock of roadway. Based on this assumption, all the deformation outside the interface is concentrated on the interface, and the shear slip is equal to the axial displacement of the textile bag. Combining (5) and (6) becomes

$$
\frac{d^{2} u}{d x^{2}}-\frac{2 h+b}{h b E} \tau(u)=0
$$

2.3. Elastic Analysis of Load Transfer between Textile Bag and Roadway. When the roadway interface is in a completely elastic state, the linear load transfer function is as follows:

$$
\tau(u)=K_{1} u .
$$

Substitute (9) into (8) and get

$$
\frac{d^{2} u}{d x^{2}}-\frac{2 h+b}{h b E} K_{1} u=0
$$

Let $\beta=\sqrt{(2 h+b) K_{1} / h b E}$, which can solve the following:

$$
u(x)=C_{1} \cosh (\beta x)+C_{2} \sinh (\beta x) .
$$

Consider the boundary conditions: $\left.\sigma_{x}\right|_{x=0}=\sigma_{P},\left.\sigma_{x}\right|_{x=l}=0$, in combination with (7) and (11).

$$
\sigma_{x}=-E \beta\left[C_{1} \sinh (\beta x)+C_{2} \cosh (\beta x)\right] .
$$

Namely, $\left.\sigma_{x}\right|_{x=0}=-E \beta C_{2}=\sigma_{P}$.

It has to be

$$
C_{2}=-\frac{\sigma_{P}}{E \beta},
$$

$$
\left.\sigma_{x}\right|_{x=l}=-E \beta\left[C_{1} \sinh (\beta l)+C_{2} \cosh (\beta l)\right]=0 .
$$

Substitute (13) into (14) and get

$$
C_{1}=\frac{\sigma_{P} \cosh (\beta l)}{E \beta \sinh (\beta l)} .
$$

Substitute (13) (15) into (12) and get

$$
\sigma_{x}=\frac{\sinh [\beta(l-x)]}{\sinh (\beta l)} \sigma_{P} .
$$

Combine (6) and (16) and get

$$
\tau_{x}=\frac{h b \beta \sigma_{P} \cosh [\beta(l-x)]}{(2 h+b) \sinh (\beta l)} .
$$

Under the condition of elastic-plastic criticality, the resistance at $x=0$ just reaches the interface ultimate bonding strength. Let $\tau(x)=\tau_{1}$, when substituted into (17), the ultimate compressive stress of the elastic state is

$$
\sigma_{P e}=\frac{(2 h+b) \tau_{1}}{h b} \tanh (\beta l) .
$$

2.4. Load Transfer Elastic-Plastic Analysis between Textile Bag and Roadway Interface. When the load is relatively large, the shear stress on the initial end side of the textile bag reaches the interface shear strength, and the interface will undergo debonding failure. And the surrounding rock will enter the stage of plastic softening. From the relation curve 
of shear stress and displacement, it can be obtained that

$$
\tau(u)=\tau_{1}-K_{2}\left(u-u_{1}\right), u_{1} \leq u \leq u_{2}
$$

Substitute (19) into (8) and get

$$
\frac{d^{2} u}{d x^{2}}+\frac{(2 h+b) K_{2}}{h b E} u-\frac{(2 h+b)\left(\tau_{1}+K_{2} u_{1}\right)}{h b E}=0
$$

Let $\gamma=\sqrt{(2 h+b) K_{2} / h b E}$, which can solve the following:

$$
u(x)=\frac{\tau_{1}}{K_{2}}+u_{1}+C_{3} \cos (\gamma x)+C_{4} \sin (\gamma x) .
$$

The derivative of (6) and (7) with respect to (21) is as follows:

$$
\begin{gathered}
\sigma_{x}=E \gamma\left[C_{3} \sin (\gamma x)-C_{4} \cos (\gamma x)\right], \\
\tau_{x}=-K_{2}\left[C_{3} \cos (\gamma x)+C_{4} \sin (\gamma x)\right] .
\end{gathered}
$$

Assuming that the length of the plastic-softening stage on the left side of the textile bag is $x_{e}$, and then it is the elastic joint deformation state. At this time, the pressure acting on the elastic part is $\sigma_{P e 1}$, and the length of the elastic stage is $l$ $-x_{e}$. From (17), the distribution law of shear stress in the elastic bonding section is

$$
\tau=\frac{h b \beta \sigma_{P e 1} \cosh [\beta(l-x)]}{(2 h+b) \sinh \left[\beta\left(l-x_{e}\right)\right]}, x>x_{e}
$$

Consider the boundary conditions.

$$
\begin{gathered}
\left.\sigma_{x}\right|_{x=0}=\sigma_{P}, \\
\left.\tau_{x}\right|_{x=x_{e}}=\tau_{1}, \\
\left.\sigma_{x}\right|_{x=x_{e}}=\sigma_{P e 1} .
\end{gathered}
$$

Substitute (25) into (22) and get

$$
C_{4}=-\frac{\sigma_{p}}{E \gamma}
$$

Combine (26), (27), (22), (23), and (24), it is determined that the length of softening section $x_{e}$ satisfies the following equation:

$$
\frac{\tau_{1}}{\beta} \tanh \left[\beta\left(l-x_{e}\right)\right]=-\frac{h b E \gamma\left[\tau_{1} \sin \left(\gamma x_{e}\right)+K_{2} C_{4}\right]}{(2 h+b) K_{2} \cos \left(\gamma x_{e}\right)} .
$$

Do the Taylor expansion on both sides of this equation.

$$
x_{e}=l-\frac{1}{\beta} \operatorname{arctanh}\left[-\frac{h b E \gamma C_{4} \beta}{(2 h+b) \tau_{1}}\right] .
$$

Substitute (30) into (23) and get

$$
C_{3}=\frac{K_{2} \sigma_{P} \sin \left(\gamma x_{e}\right) / E \gamma-\tau_{1}}{K_{2} \cos \left(\gamma x_{e}\right)}
$$

Substitute (28) and (31) into (22) and (23) and get

$$
\sigma_{x}=E \gamma\left[\frac{K_{2} \sigma_{P} \sin \left(\gamma x_{e}\right) / E \gamma-\tau_{1}}{K_{2} \cos \left(\gamma x_{e}\right)} \sin (\gamma x)+\frac{\sigma_{P}}{E \gamma} \cos (\gamma x)\right],
$$

$$
\tau_{x}=-K_{2}\left[\frac{K_{2} \sigma_{P} \sin \left(\gamma x_{e}\right) / E \gamma-\tau_{1}}{K_{2} \cos \left(\gamma x_{e}\right)} \cos (\gamma x)-\frac{\sigma_{P}}{E \gamma} \sin (\gamma x)\right] .
$$

2.5. Residual Shear Analysis between Textile Bag and Roadway. If the load increases further, the left side of the textile bag will enter the residual deformation stage. And $x_{r}$ is the length of the residual shear section, that is, the left side of the textile bag only has friction. From the relation curve of shear stress and displacement, it can be obtained that

$$
\tau(u)=\tau_{2}
$$

Substitute (34) into (8) and get

$$
\frac{d^{2} u}{d x^{2}}-\frac{2 h+b}{h b E} \tau_{2}=0
$$

which can solve

$$
u(x)=\frac{(2 h+b) \tau_{2}}{h b E} x^{2}+C_{5} x+C_{6}
$$

Combine (7) and (36) and get

$$
\sigma_{x}=-\frac{(2 h+b) \tau_{2}}{h b} x+C_{5}
$$

Consider the boundary conditions.

$$
\left.\sigma_{x}\right|_{x=0}=\sigma_{P}
$$

Joint (37) and (38) obtained $C_{5}=\sigma_{P}$.

Namely,

$$
\begin{gathered}
\sigma_{x}=-\frac{(2 h+b) \tau_{2}}{h b} x+\sigma_{P} . \\
\tau_{x}=\tau_{2} .
\end{gathered}
$$

When it just enters the debonding stage, that is, at $x=0$, according to (33), let $\tau_{x}=\tau_{2}$, and the ultimate compressive stress when entering the residual shear stage can be obtained.

$$
\sigma_{P p}=\frac{E \gamma\left[\tau_{1}-\tau_{2} \cos \left(\gamma x_{e}\right)\right]}{K_{2} \sin \left(\gamma x_{e}\right)} .
$$



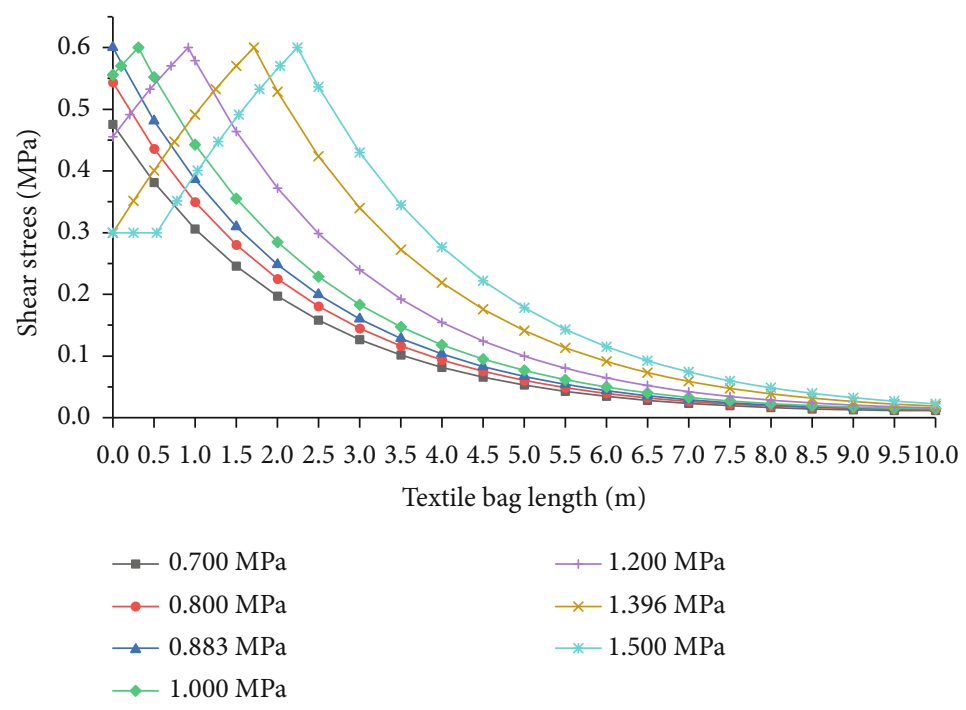

Figure 3: Shear stress distribution curve of textile bag under different loads.

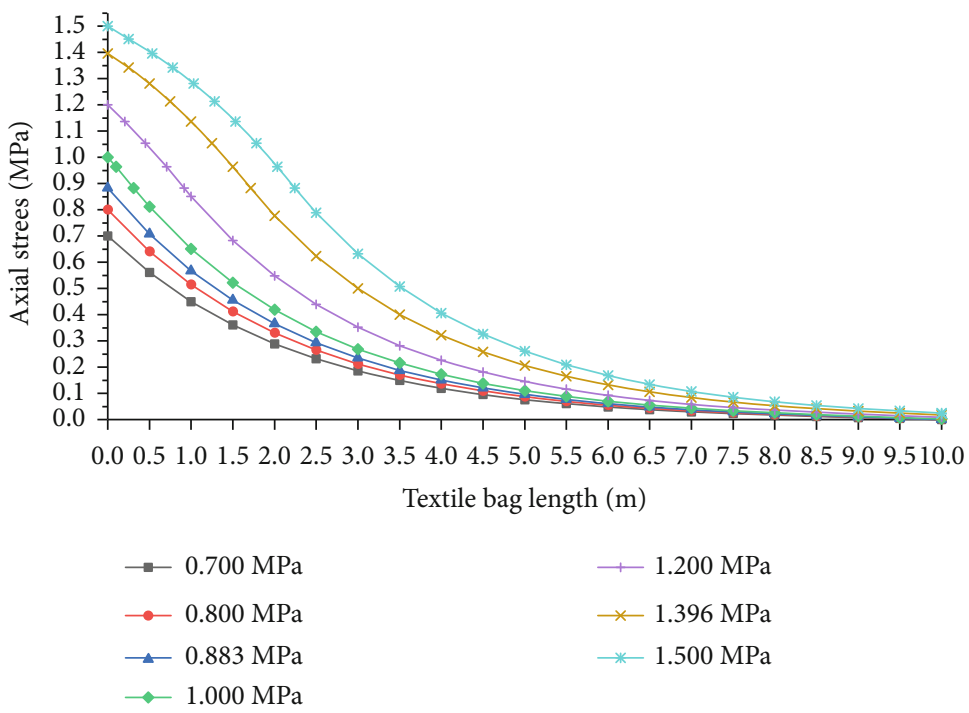

FIgURE 4: Axial stress distribution curve of textile bag under different loads.

The length of the residual shear part can be obtained by combining (39) and (41).

$$
x_{r}=\frac{h b \sigma_{P} K_{2} \sin \left(\gamma x_{e}\right)-h b E \gamma\left[\tau_{1}-\tau_{2} \cos \left(\gamma x_{e}\right)\right]}{(2 h+b) \tau_{2} K_{2} \sin \left(\gamma x_{e}\right)} .
$$

2.6. Calculation and Analysis of Water Resistance Effect of Textile Bag. Parameter value: the length of textile bag $l$ is $10 \mathrm{~m}$, the width $b$ is $5 \mathrm{~m}$, the height $h$ is $4 \mathrm{~m}$, the elastic modulus $E$ is $2000 \mathrm{MPa}, K_{1}=600 \mathrm{MPa} / \mathrm{m}, K_{2}=300 \mathrm{MPa} / \mathrm{m}, \tau_{1}$ $=0.6 \mathrm{MPa}$, and $\tau_{2}=0.3 \mathrm{MPa}$.

According to the above parameters, by substituting equation (18) into the above parameters, the ultimate compressive stress of the textile bag during the whole bonding process is $\sigma_{P e}=0.883 \mathrm{MPa}$. According to equations (32) and (33), the ultimate compressive stress of the textile bag when it enters the residual shear section is $\sigma_{P p}=1.396 \mathrm{MPa}$; at this time, the softening stage is $x_{e}=1.71 \mathrm{~m}$. Figure 3 shows the distribution curve of shear stress along the length of the textile bag when the hydraulic stress is $0.700 \mathrm{MPa}, 0.800 \mathrm{MPa}, 0.883 \mathrm{MPa}$, $1.000 \mathrm{MPa}, 1.200 \mathrm{MPa}, 1.396 \mathrm{MPa}$, and $1.500 \mathrm{MPa}$, respectively. Figure 4 shows the distribution curve of axial stress of the textile bag under the action of the above hydraulic stress.

As can be seen from the figure, the distribution of shear stress and axial stress around the textile bag has the following characteristics:

(1) When the hydraulic stress $\sigma_{P} \leq 0.883 \mathrm{MPa}$, the textile bag is in the elastic bonding stage. The lateral resistance forms peak value on the initial end side of the textile bag, gradually decreases towards the end and tends to 0 . With the increase of water pressure, the 


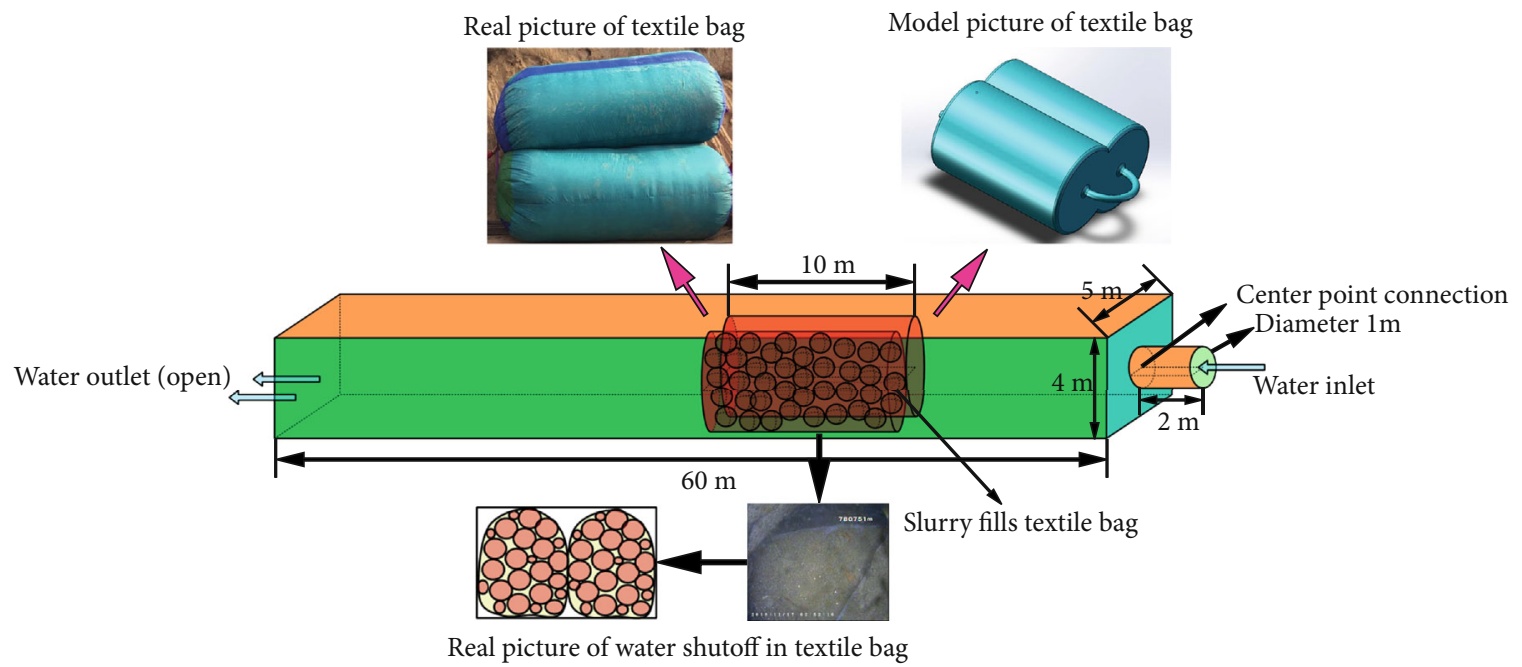

Figure 5: Model diagram of textile bag for large passage through water.

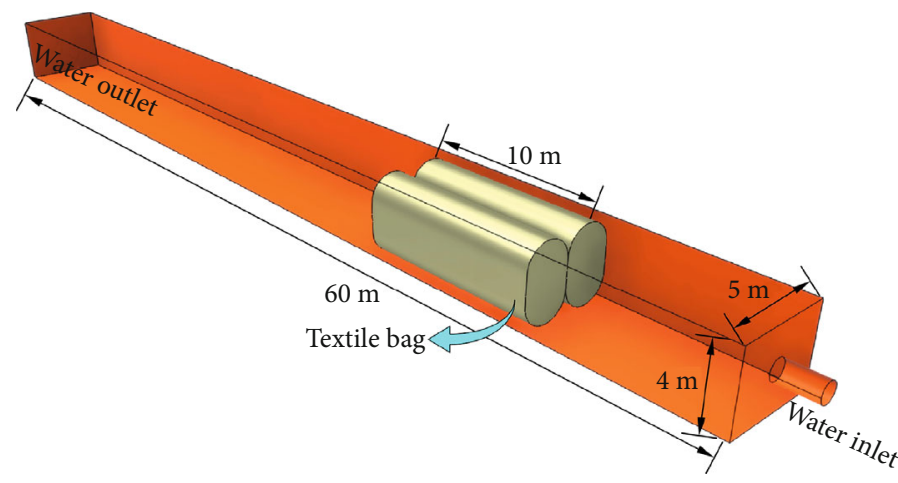

FigURE 6: Numerical simulation model diagram.

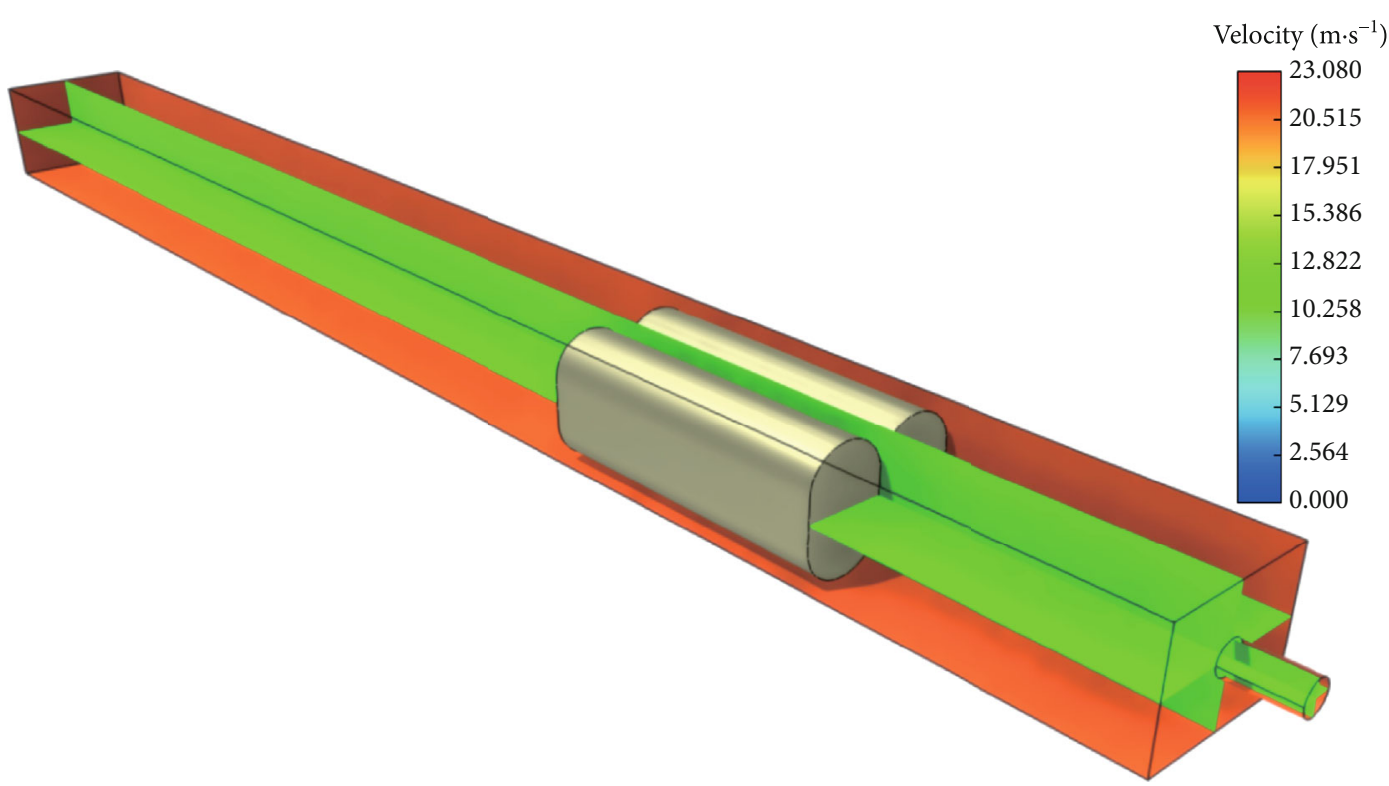

Figure 7: Initial flow field model. 


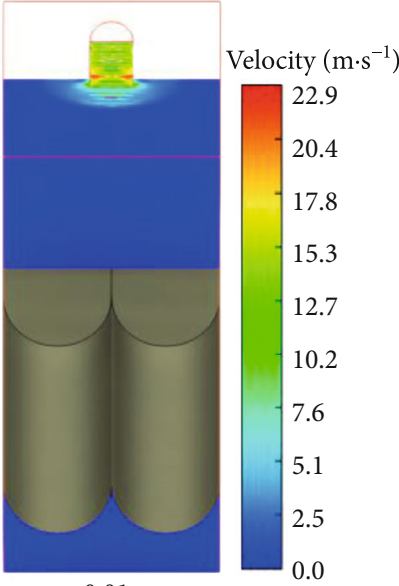

$0.01 \mathrm{~s}$

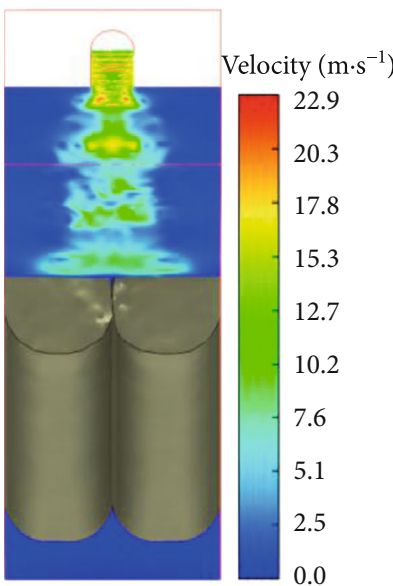

0.19 s

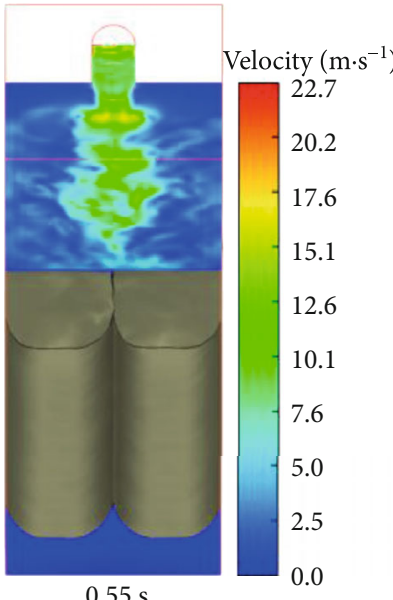

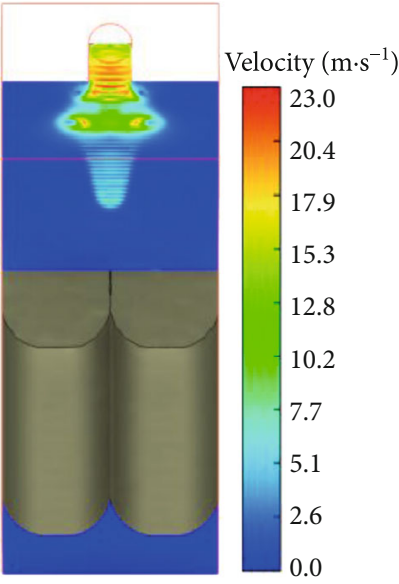

$0.05 \mathrm{~s}$

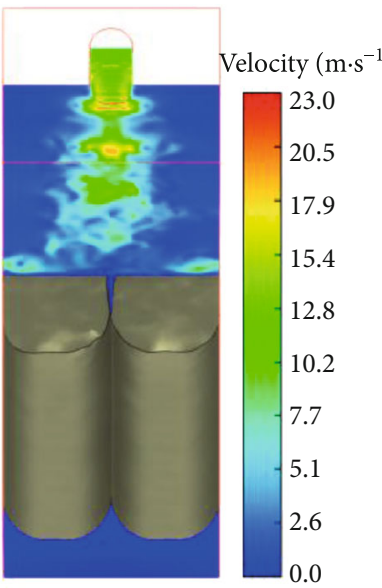

$0.23 \mathrm{~s}$

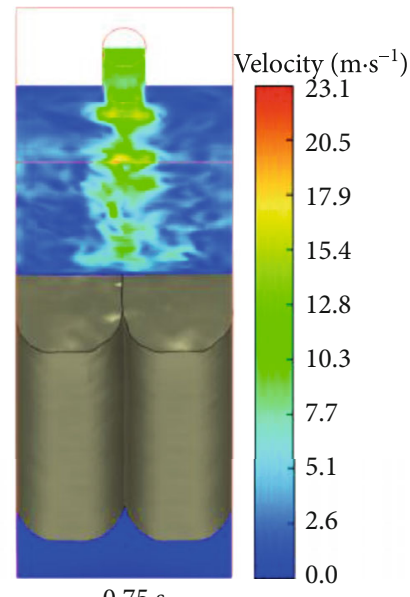

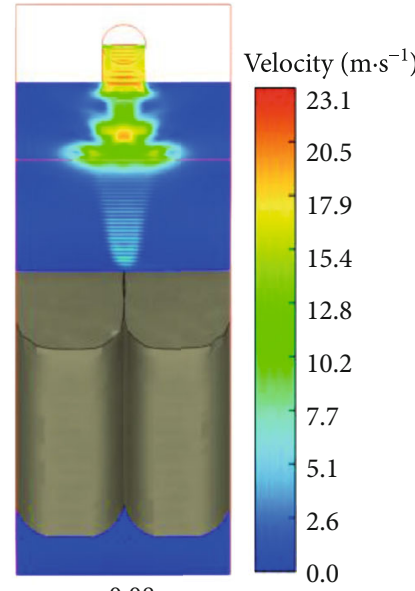

$0.08 \mathrm{~s}$

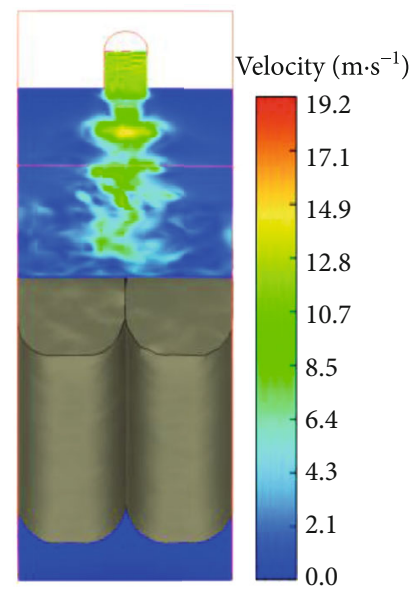

$0.35 \mathrm{~s}$

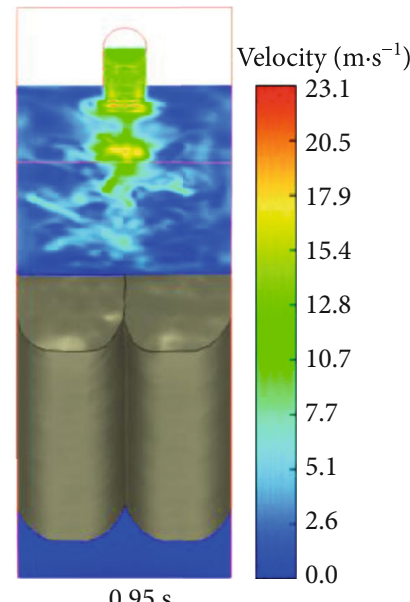

$0.95 \mathrm{~s}$

FIGURE 8: Deformation rule of textile bag was observed from the upward angle of the bottom of roadway.

maximum shear stress on the initial end side of the textile bag also increases accordingly. When the maximum shear stress increases to the peak shear strength value $\tau_{1}$ at the interface, it does not increase. The axial stress of the corresponding textile bag gradually decreases to the end and finally approaches 0
(2) When the $0.883 \mathrm{MPa} \leq \sigma_{P} \leq 1.396 \mathrm{MPa}$, the initial end side of the textile bag enters the elastic-plastic softening stage. In this case, the lateral resistance peak is not formed on the initial end side of the textile bag, but the shear stress peak is formed at the elasticplastic boundary, forming a unimodal curve. With the increase of hydraulic stress, the shear stress on 

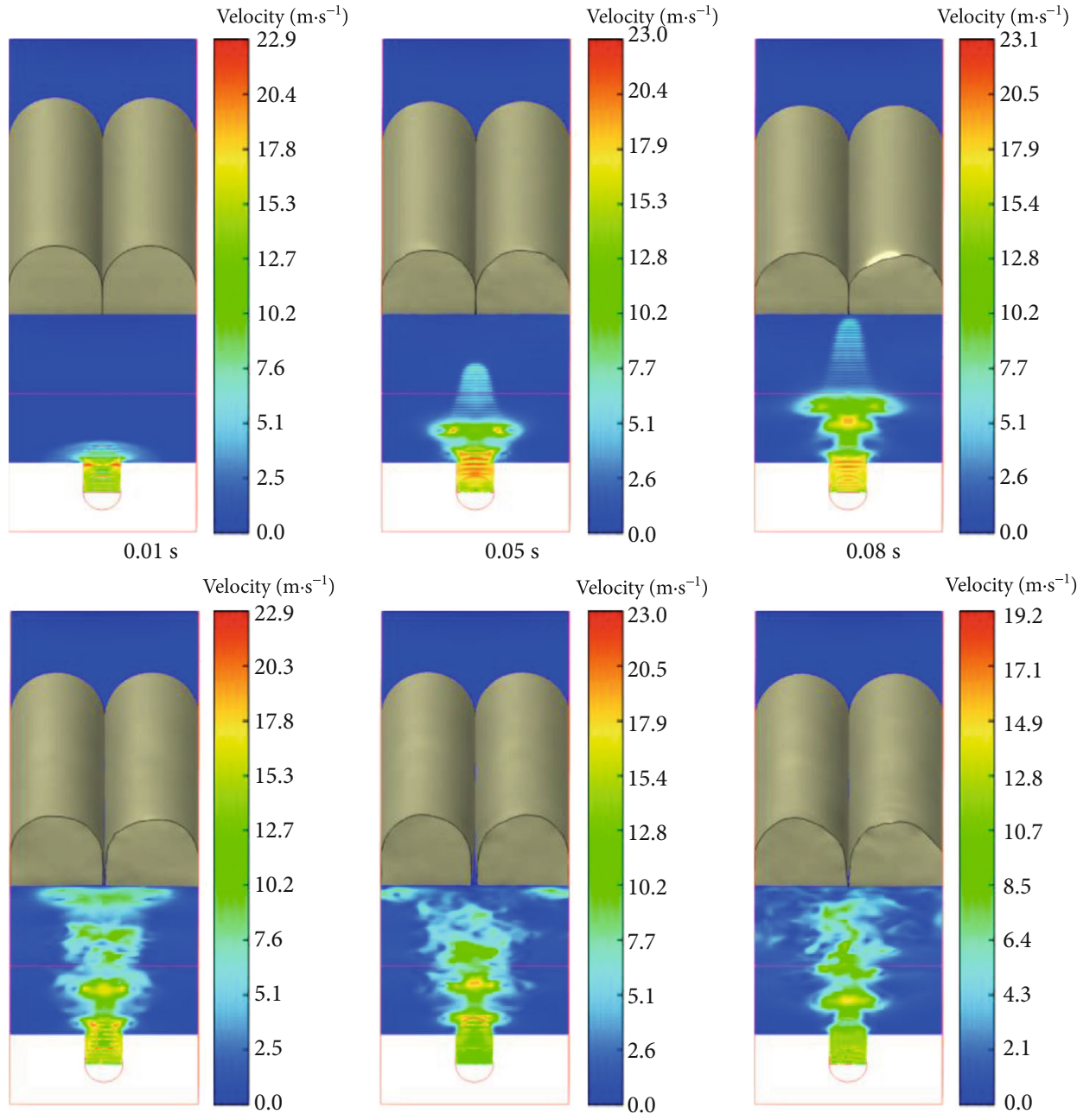

$0.19 \mathrm{~s}$ Velocity $\left(\mathrm{m} \cdot \mathrm{s}^{-1}\right)$
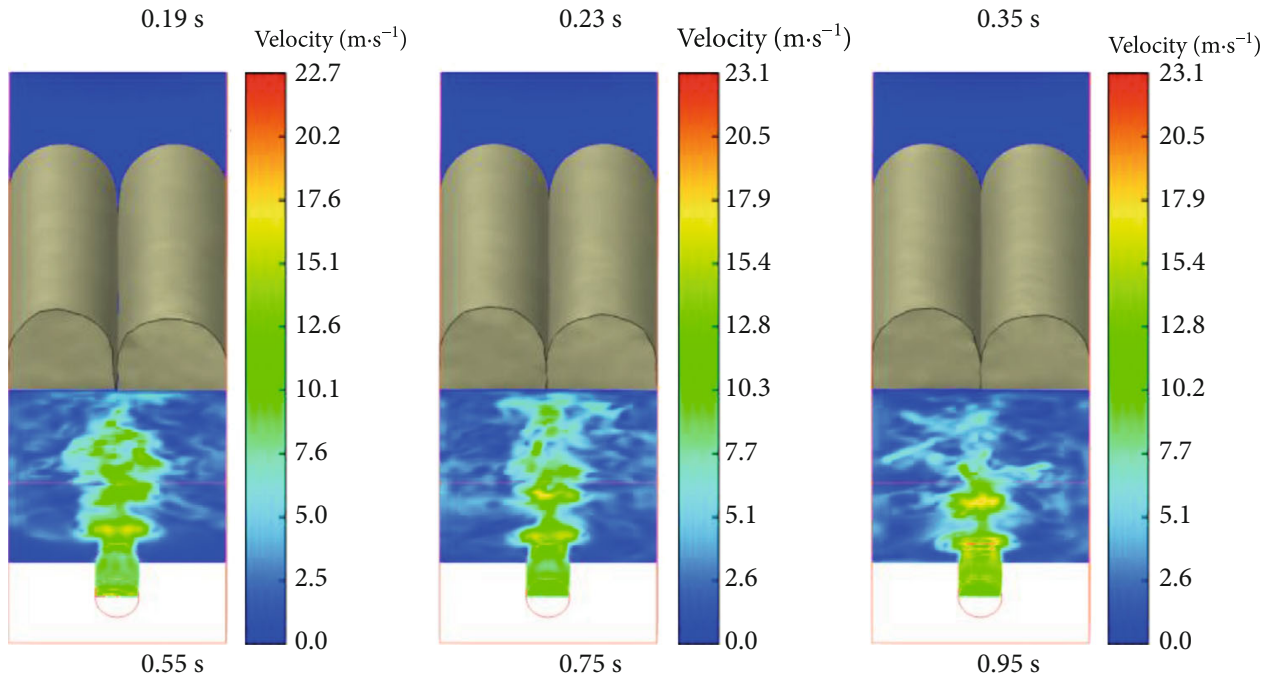

FIGURE 9: Deformation rule of textile bag was observed from the overlooking angle of the roadway top.

the initial end side of the textile bag decreases continuously. When the shear stress on the initial end side of the textile bag decreases to the interface residual strength $\tau_{2}$, it will no longer decrease. But the peak shear stress gradually moves to the end side of the textile bag. At this time, the axial stress on the initial end side forms a convex curve and then connects to the concave curve of the elastic bonding section and finally approaches 0

(3) When the $\sigma_{P} \geq 1.396 \mathrm{MPa}$, the initial end side of the textile bag enters the residual stage. At this point, 

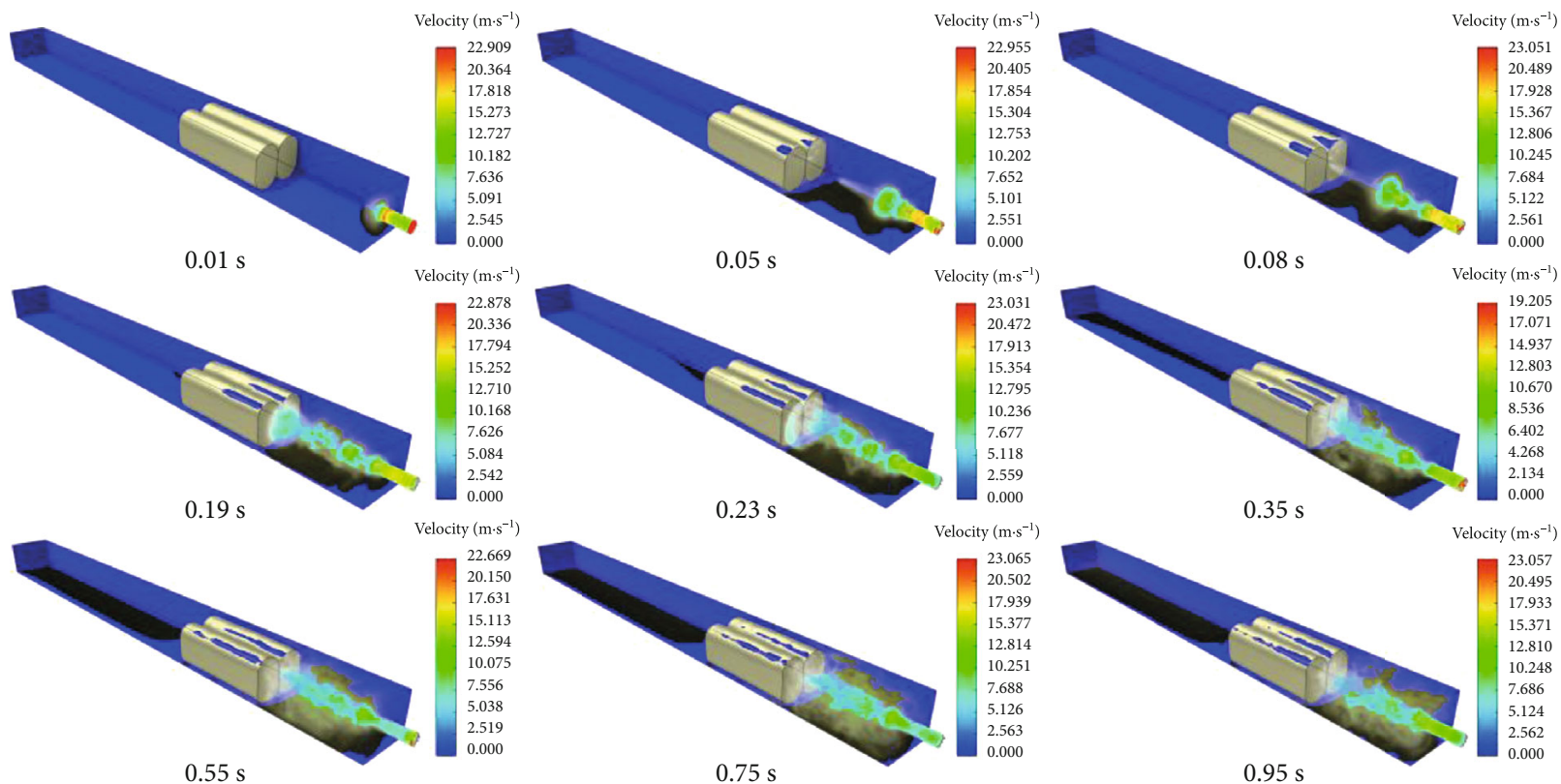

Figure 10: Deformation rule of the textile bag was observed from the oblique above the water inlet.

the shear stress on the initial end side of the textile bag does not change and is the interface residual strength $\tau_{2}$. The peak shear stress still moves to the end side of the textile bag with the increase of water pressure. The middle segment shows an ascending curve and then connects the attenuation curve of the bonding segment after reaching the peak value. At this point, the axial stress on the initial end side of the textile bag decreases linearly, and then the curve of the connecting elastic-plastic stage decreases

\section{Numerical Simulation Analysis of Water Resistance Effect of Textile Bag in Water Passage}

3.1. Software Introduction. XFlow is a powerful software application that uses patented particle-based, complete Lagrangian functions to simply tackle traditional complex computational fluid dynamics (CFD) problems in engineering, design, science, and architecture. XFlow has the ability to simulate gas and liquid flows, heat and mass transfer, moving bodies, polyphase physics, acoustics, and fluid structure interactions. Most of the fluid modeling techniques in the market are based on the traditional meshing techniques. It has encountered serious difficulties in dealing with the changes of topological regions, variable boundaries, and fluid-solid coupling. The challenge of traditional CFD technology is the grid discrete technology based on spatial regions. The reliability of the solution depends on the quality of the grid to a large extent, and it usually takes a lot of engineering time to create a good grid during CFD analysis. However, XFlow is a CFD software system that provides effective methods to solve complex problems including variable boundary, free surface, and fluid-solid coupling in complex geometric areas. It enables computational fluid dynamics (CFD) analysis to achieve complex modeling in a straightfor- ward and understandable way, minimizing the number of algorithm parameters. Avoid the traditional time-intensive matching approach.

3.2. Selection of Numerical Simulation Parameters. According to the deformation characteristics of seepage field and hydraulic force field caused by controlled grouting closure of the water passage, XFlow numerical simulation method is adopted to construct and simplify the model, with fewer parameters and relatively simple. It is necessary to consider boundary conditions, initial conditions, model size, flow field parameters, and other influencing factors to build a reasonable numerical analysis model.

This research is based on a controlled grouting plugging water channel tunnel as the research object. The purpose is to realize the simulation analysis of the stability of the textile bag with small flow rate and low pressure and large flow rate and high pressure by using the XFlow calculation software. It is necessary to highlight the main factors affecting the analysis results and to abstract out a reasonable calculation model by ignoring the secondary factors. Combining the theoretical analysis with practical engineering background, the XFlow numerical simulation model of this project selected the roadway height of $4 \mathrm{~m}$, width of $5 \mathrm{~m}$, and length of $60 \mathrm{~m}$. The water passage entrance was located in the middle right side of the roadway model ( $2 \mathrm{~m}$ in length and $1 \mathrm{~m}$ in diameter), and the size of textile bag was designed with a length of $10 \mathrm{~m}$. The cross section circumference of the double textile bag can contact the two sides and the roof and floor of the roadway. In the model, the right side of the roadway is the water inlet. And the left side is the open water outlet. Figure 5 shows the model diagram of textile bag for large passage through water.

The establishment of mathematical model is the first task of computer numerical simulation. The correctness of the model establishment is the prerequisite for obtaining the results consistent with the actual calculation. Under the 


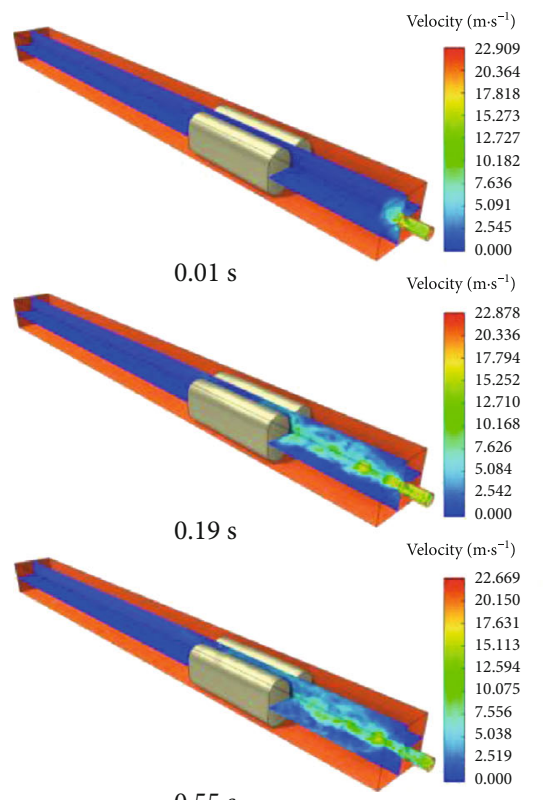

$0.55 \mathrm{~s}$
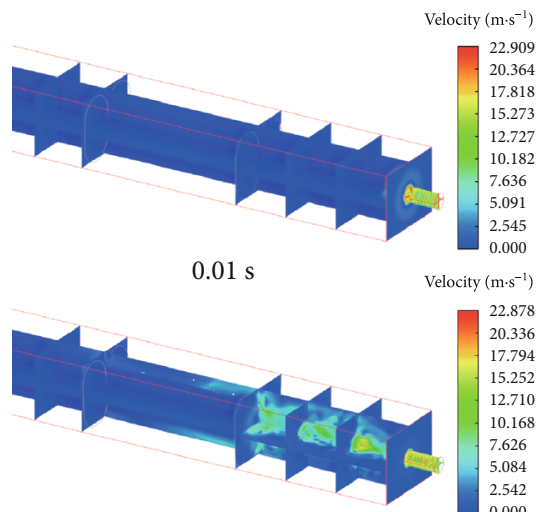

$0.19 \mathrm{~s}$

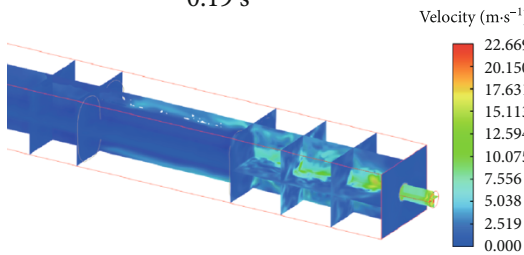

$0.55 \mathrm{~s}$

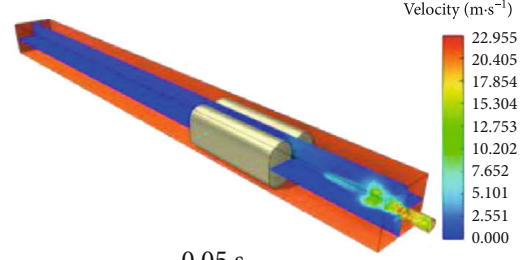

$0.05 \mathrm{~s}$

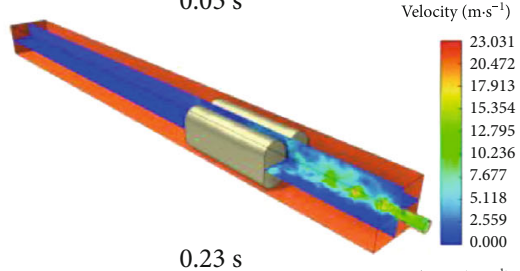

$0.23 \mathrm{~s}$

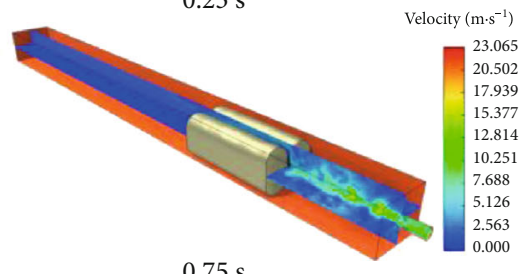

$0.75 \mathrm{~s}$

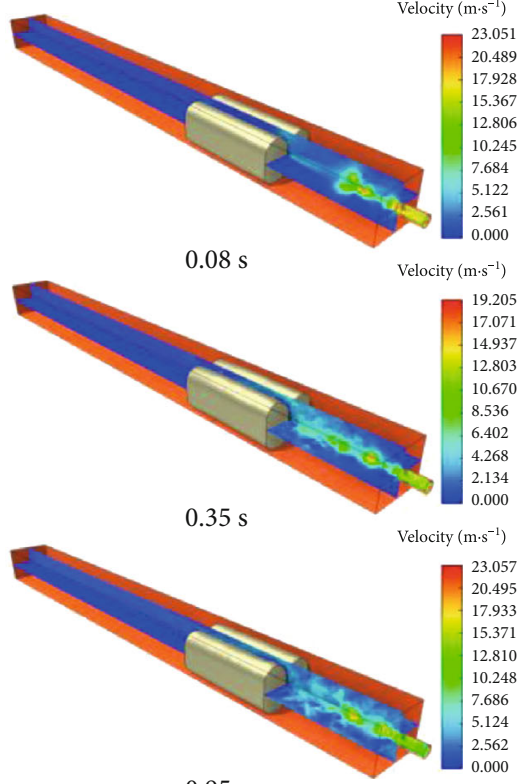

$0.95 \mathrm{~s}$

(a)
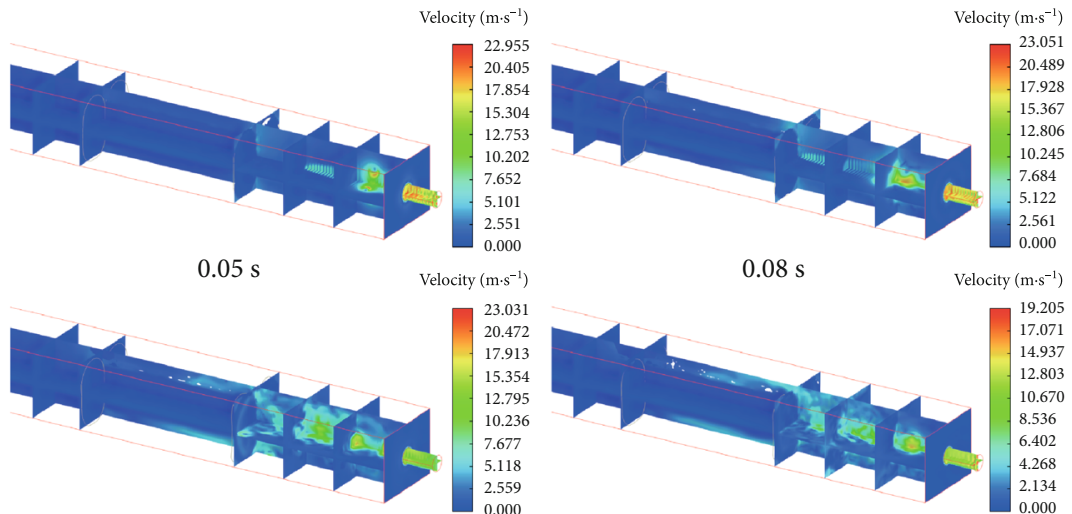

$0.23 \mathrm{~s}$

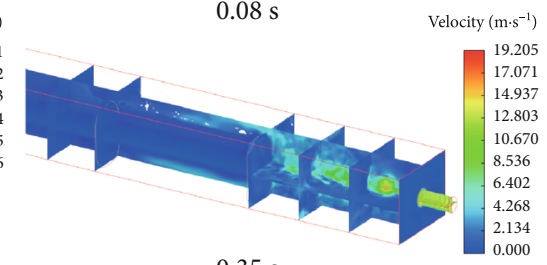

$0.35 \mathrm{~s}$

Velocity $\left(\mathrm{m} \cdot \mathrm{s}^{-1}\right)$

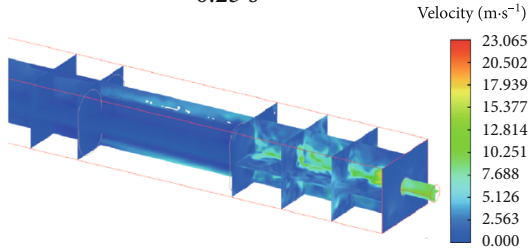

$0.75 \mathrm{~s}$

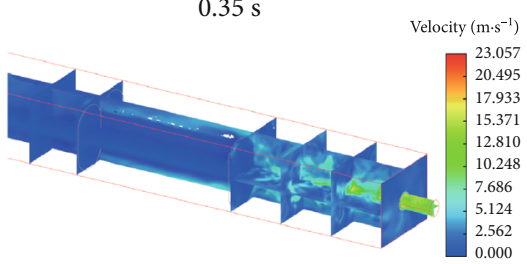

$0.95 \mathrm{~s}$

(b)

Figure 11: Variation of flow velocity over time. (a) Perspective view and (b) a cross-sectional view.

condition of reflecting the original modeling conditions as much as possible, some assumptions and simplifications are made to facilitate the simulation analysis and calculation. Figure 6 shows the numerical simulation model.

3.3. Analysis of Simulation Results. To textile bag in the block water law of water channel simulation so far has not revealed. Therefore, with this topic in a water tunnel as the research object, the numerical calculation model is set up. In roadway position on the right side of $10 \mathrm{~m}$ distance model set initial flow field section, water inlet pressure designs three kinds of operating mode, respectively, $0.3 \mathrm{MPa}, 0.5 \mathrm{MPa}$, and
0.7 $\mathrm{MPa}$, and the computing time $1 \mathrm{~s}$. Considering the three working conditions, the flow field velocity, flow field pressure, and textile bag stress characteristics are similar. Therefore, $0.7 \mathrm{MPa}$ was selected as the key analysis object to analyze the water-blocking effect, stress, and flow field distribution of the textile bag in the passage. Figure 7 shows the initial flow field model of the numerical model.

3.3.1. Deformation Morphology and Flow Field Distribution Rule of Textile Bag. Figures 8-10 show the evolution rule of the seepage field of the textile bag in the water passage. The actual evolution is divided into 100 steps, $0.01 \mathrm{~s}$ for each step, 


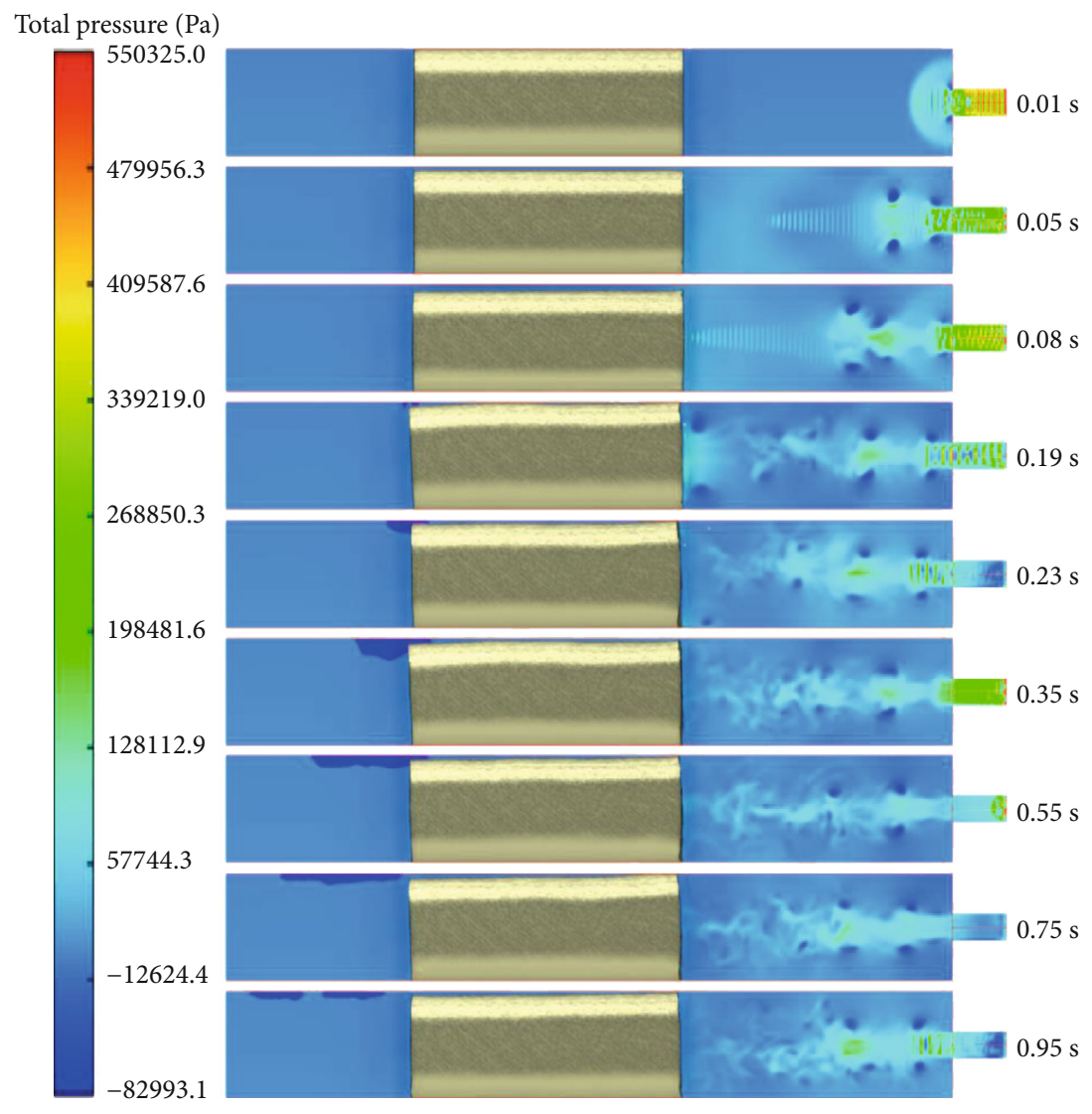

Figure 12: Evolution law of water pressure at different times.

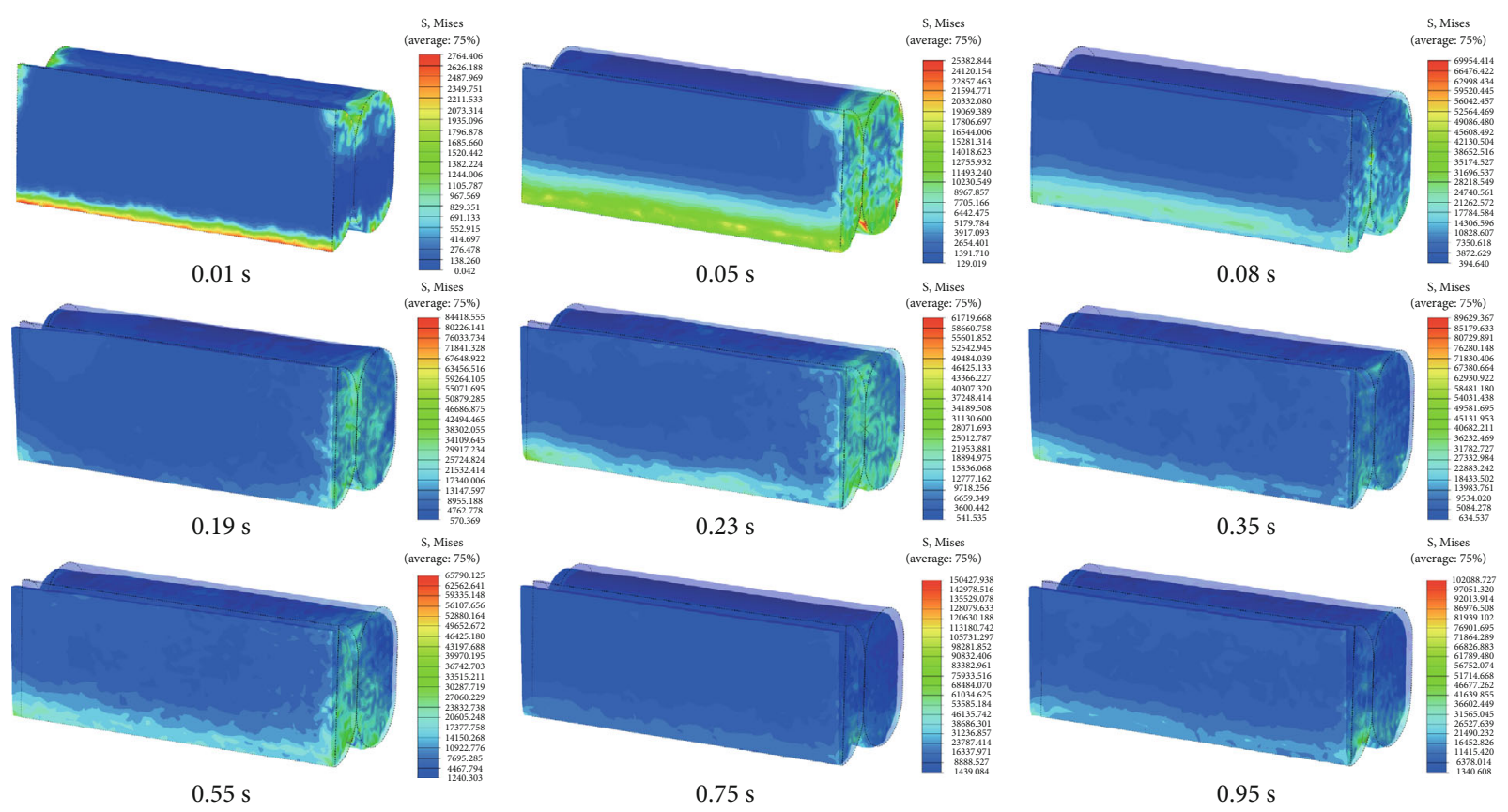

Figure 13: Impact law of Mises on textile bag at different times. 


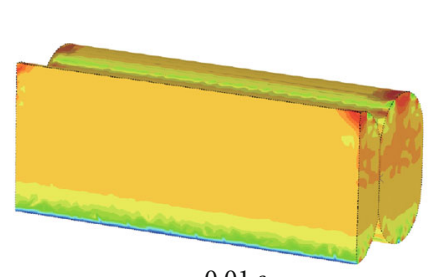

$0.01 \mathrm{~s}$

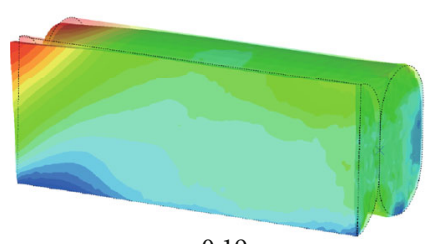

$0.19 \mathrm{~s}$

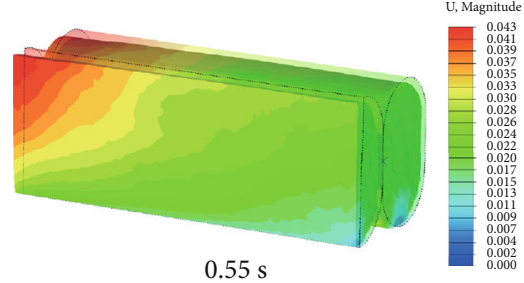

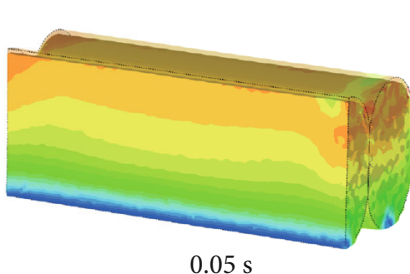

$0.05 \mathrm{~s}$

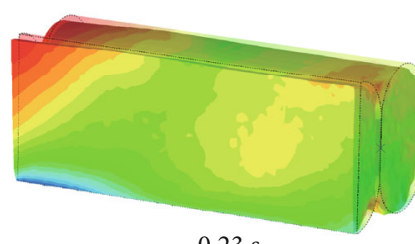

$0.23 \mathrm{~s}$

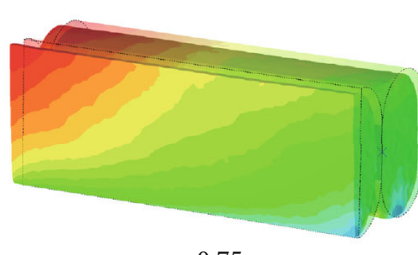

$0.75 \mathrm{~s}$
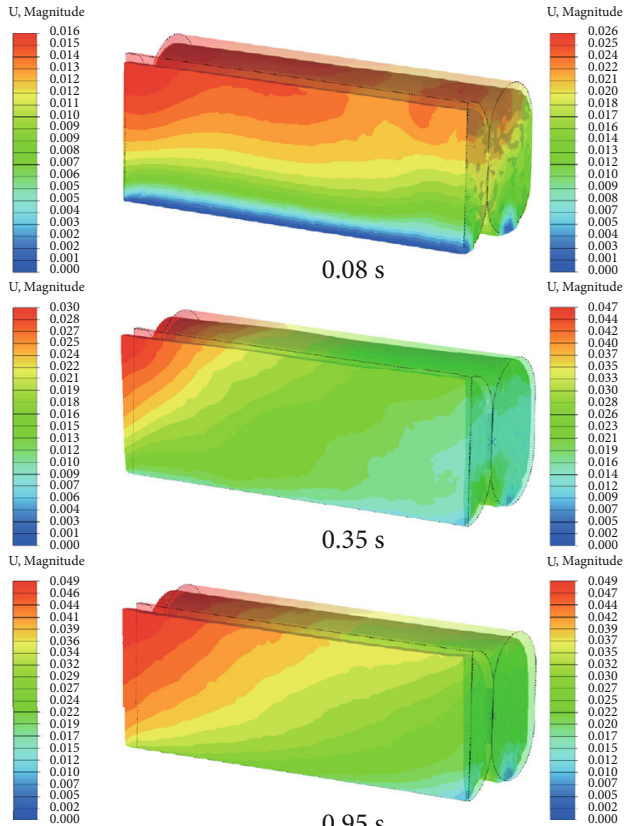

Figure 14: Deformation law of textile bag at different times.

and 9 time points are selected for study. The three figures show the influence of the flow field at different times on the deformation and distribution of the textile bag. Figure 8 shows the deformation of the textile bag observed from the upward angle at the bottom of the roadway. Figure 9 shows the deformation of the textile bag observed from the overlooking angle of the roadway top. Figure 10 shows the deformation of the textile bag observed from the oblique above the water inlet. Figure 11 shows the variation of flow velocity over time. Figure 12 shows the evolution of water pressure at different times.

As can be seen from Figures 8-12, when the water is ejected from the water inrush outlet at $0.7 \mathrm{MPa}$, the water will spread out in a fan-shaped way. At this time, it is far away from the textile bag, and the flow field does not affect the textile bag. When $t$ is $0.05 \mathrm{~s}$, the water column formed by the high-speed water flow is approximately horizontal due to the textile bag blocking the tunnel, which can extrude the blocked water inside the tunnel. According to the shape of the textile bag, it has slightly deformed at this time. And the deformation occurs mainly at the place where the textile bag and the surrounding rock are not blocked, which is mostly the overflow point. When $t$ is $0.08 \mathrm{~s}$, the first wave of obvious water flow reaches the edge of the textile bag, and at this time, obvious extrusion deformation occurs near the 6 overflow points. When time $t$ reaches $0.19 \mathrm{~s}$, the water flow is blocked by the textile bag. The flow field forms a significant reflected water wave on the surface of the textile bag. Due to the impact of water pressure, the stress surface of the textile bag will sag inwards, and the sag degree is mainly affected by the elastic modulus of the textile bag and the whole slurry inside and the grouting slurry pressure. Then, the high headwater ejected from the water inlet will then pressurize the water retention between the textile bag and the water inlet.
However, new water leakage points will be formed when the textile bag is not completely in contact with the roof, floor, and two sides of the roadway. But the water flow from the leakage point has a certain pressure and flow rate. And compared with the water pressure and flow before the sealing of the textile bag, the water pressure and flow rate are significantly lower.

3.3.2. Mechanical Evolution Characteristics of Internal Structure of Textile Bag. Figure 13 shows the influence of water flow fields at different times on the deformation of textile bag. Figure 14 shows the deformation law of textile bag at different times.

It can be seen from Figures 13 and 14 that when $t$ is $0.01 \mathrm{~s}$, the high-pressure water just gushed out from the water inlet. At this point, the flow field has little influence on the stress of the textile bag. Because the textile bag itself has a certain gravity influence, and the textile bag itself is flexible material, the friction resistance between the textile bag and surrounding rocks mainly affects the roadway floor and the two sides. And the edge of the textile bag near the overflow point has a great influence. When $t$ is $0.05 \mathrm{~s}$, it can be seen from the figure that the water flow has a significant influence on the water pressure at the water surface of the textile bag. When $t$ is $0.05 \sim 0.23 \mathrm{~s}$, the textile bag is affected by the flow pressure, and an upward slope will be formed on the side facing the water surface of the textile bag. This increases the force of the water flow on the water surface of the textile bag, and the end of the textile bag has a shape of "high in front and low in back" due to the great friction resistance with the bottom plate. However, the pressure difference of the water outlet head is large, and the water flow pattern in the waterblocking section will change with the shape of the stressed slope surface of the textile bag. When the top of the textile 


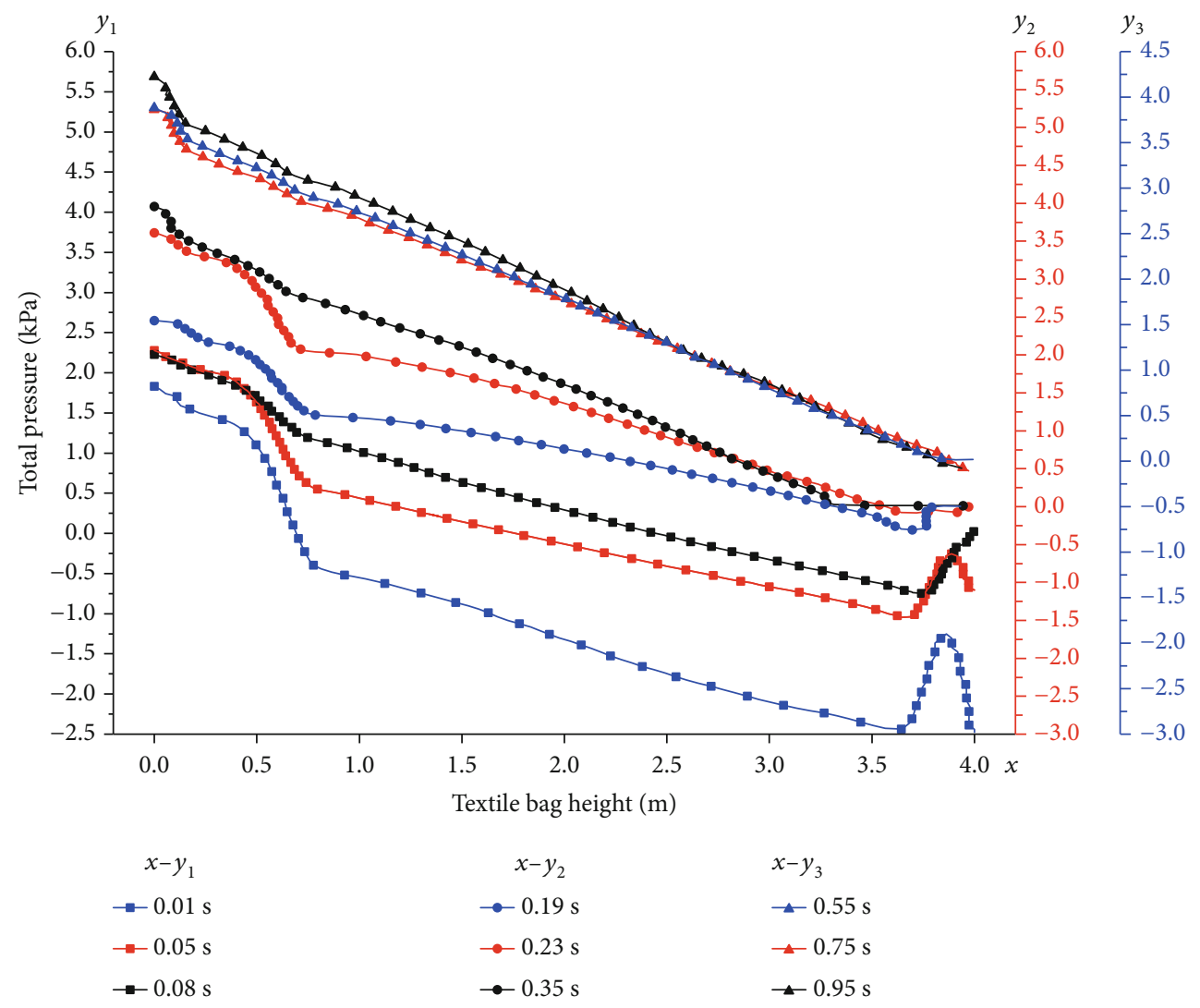

(a)
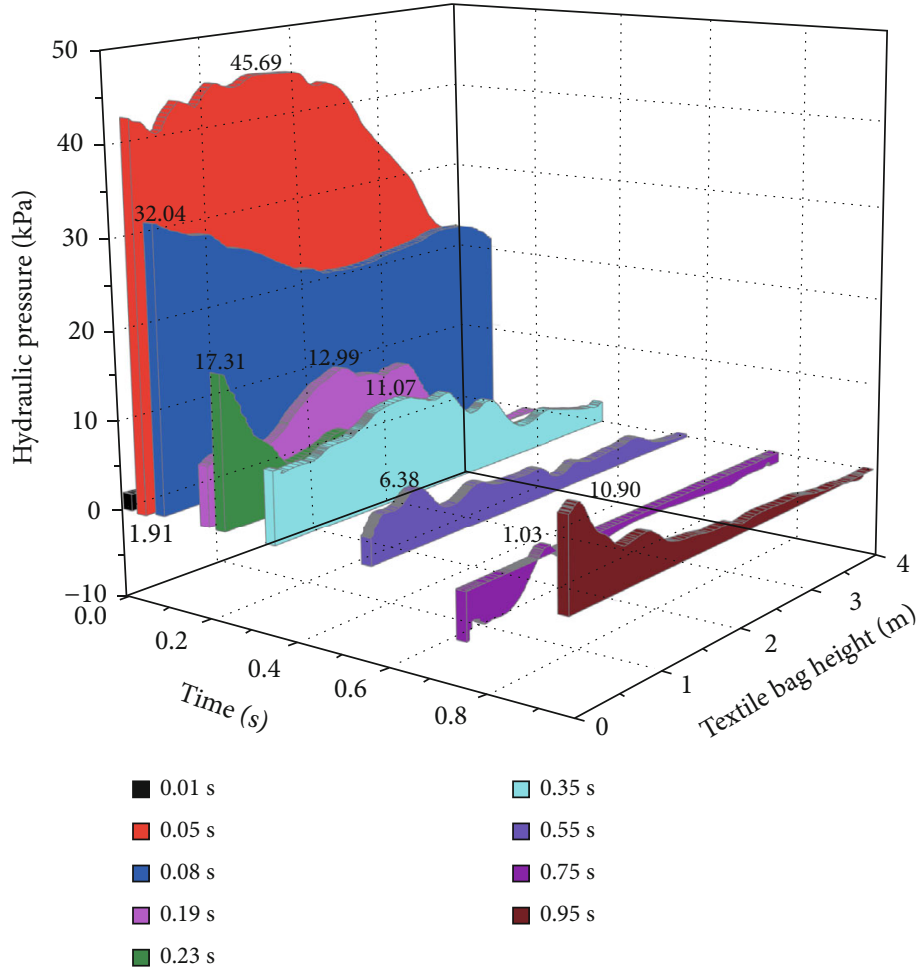

(b)

Figure 15: Continued. 


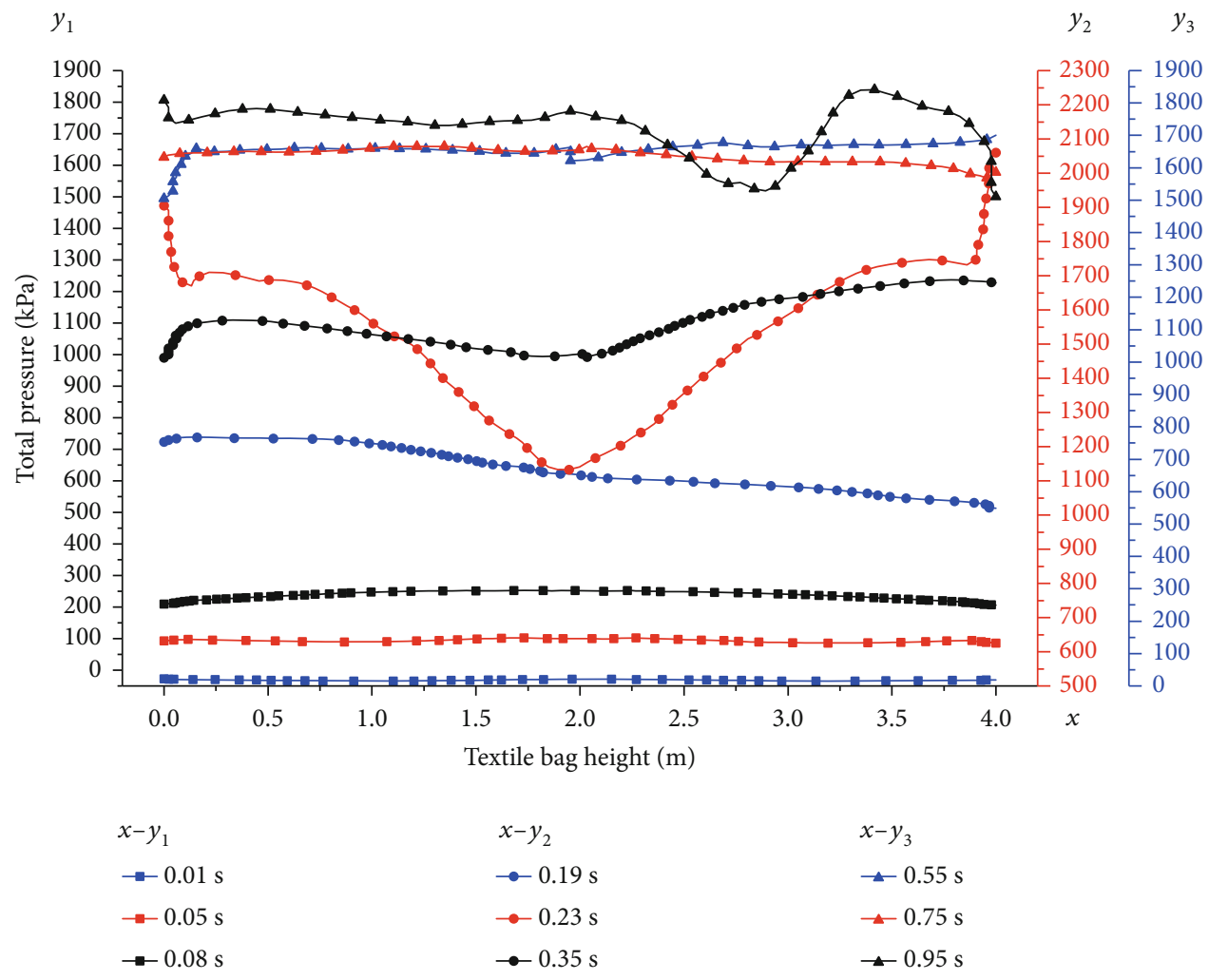

(c)

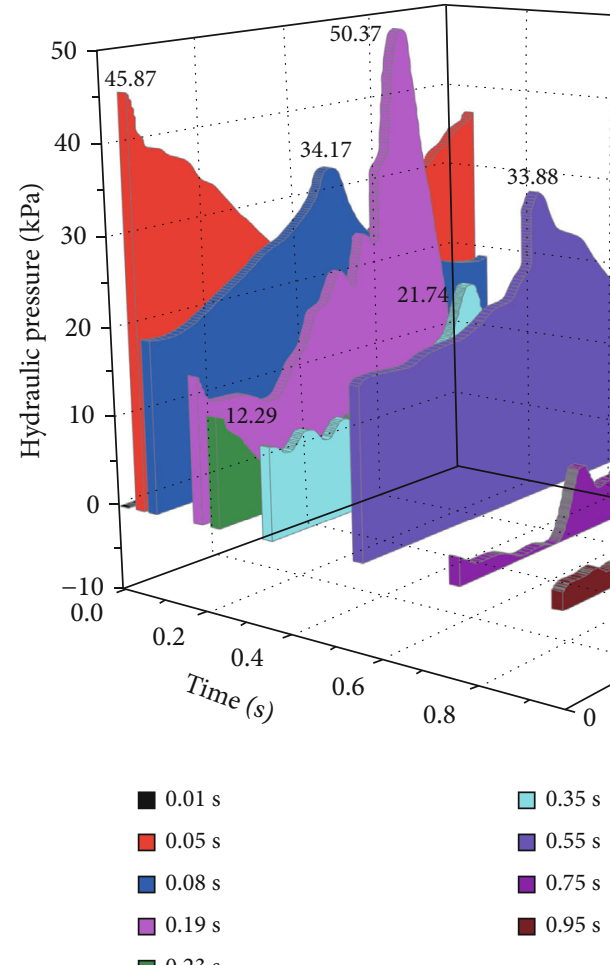

(d)

FIGURE 15: Longitudinal water pressure of textile bag under different times. (a) The right side of the end, (b) the left side of the end, (c) middle right, and (d) middle left. 


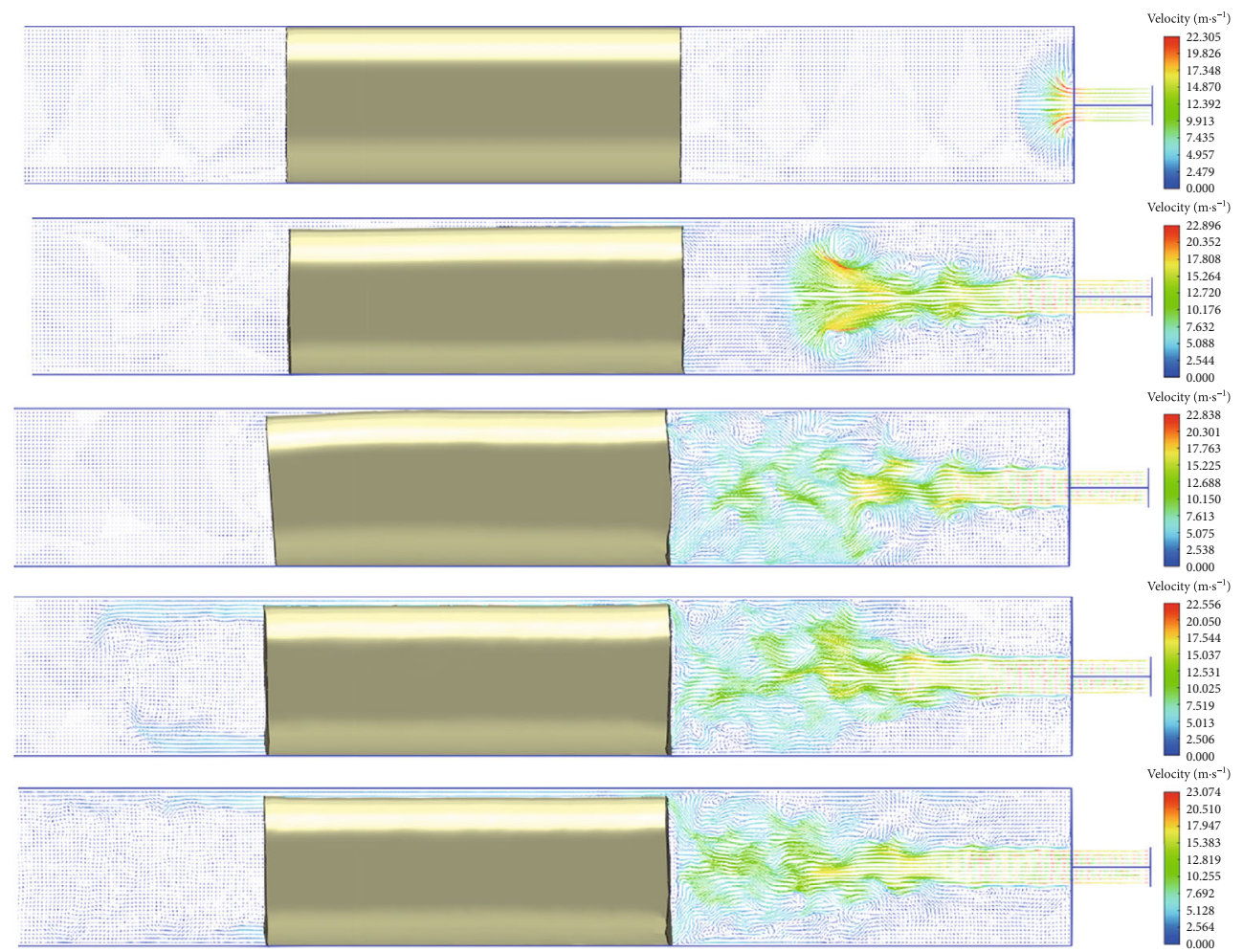

(a)

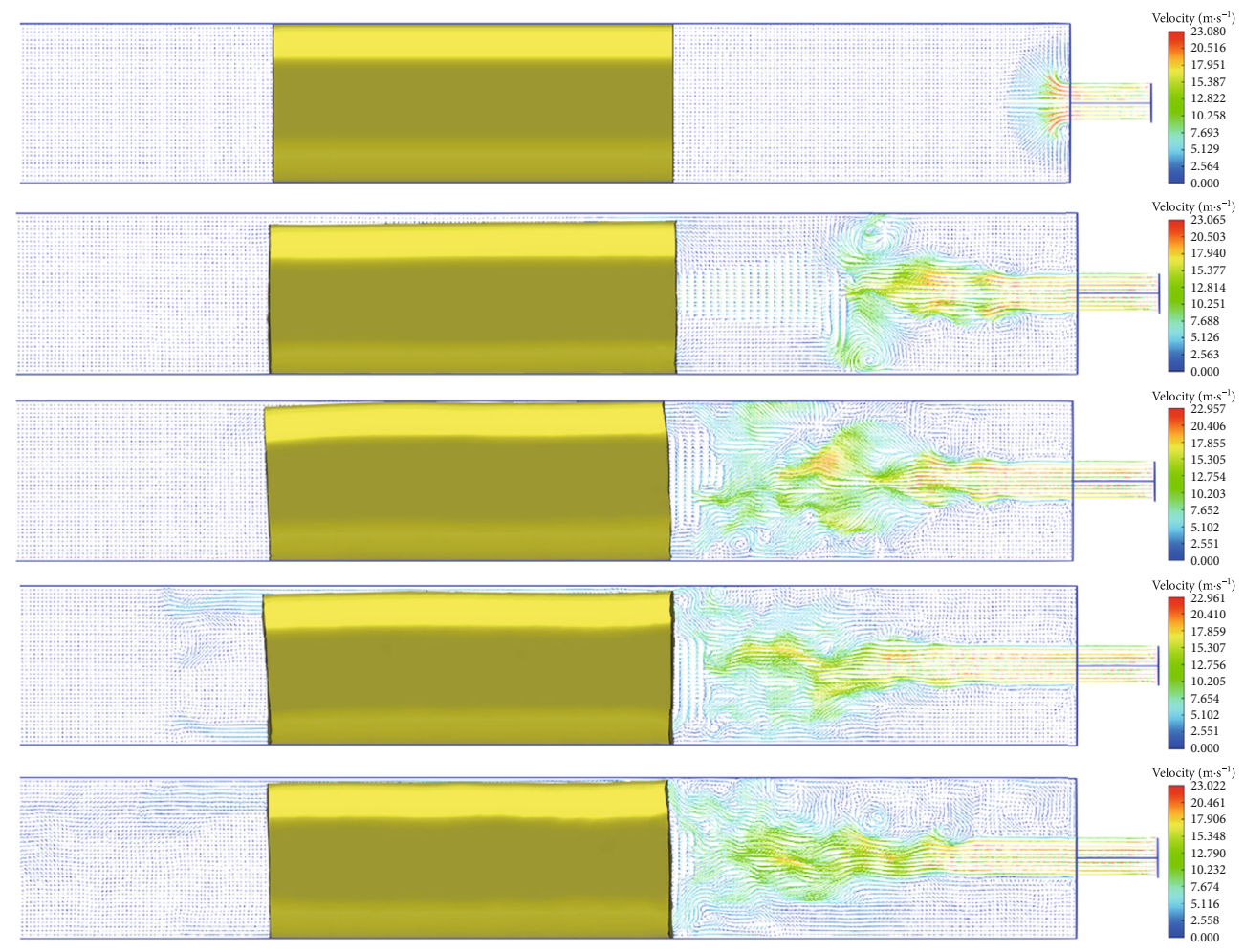

(b)

Figure 16: Continued. 


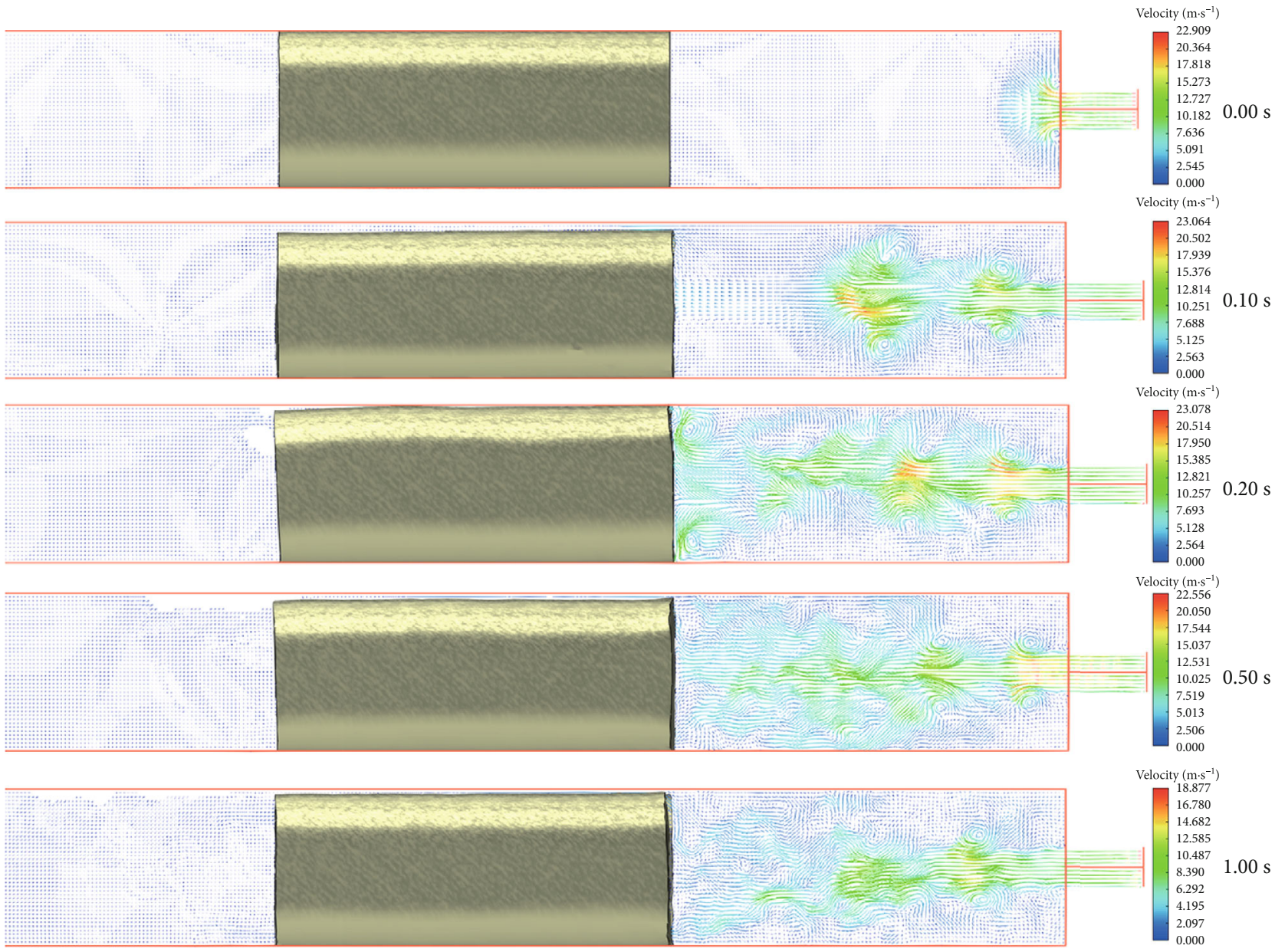

(c)

Figure 16: Influence of flow field under different water pressure on the deformation of textile bag. (a) $0.3 \mathrm{MPa}$, (b) $0.5 \mathrm{MPa}$, and (c) $0.7 \mathrm{MPa}$.

bag is not compacted, the high-pressure water will overflow into the tunnel along the top of the textile bag and other leakage points.

3.3.3. Variation of Water Pressure at the Edge of Textile Bag. Figure 15 shows the longitudinal water pressure of the textile bag at different times. Figure 15(a) shows the water pressure at the vertical section of the textile bag ( $1.25 \mathrm{~m}$ away from the center line). Figure 15(b) shows the water pressure at the vertical section in the middle of the textile bag.

It can be seen from Figures 15(a) and 15(b) that the forces on both sides of the textile bag are mainly in the form of trapezoid or triangle. This is closely related to the water flow velocity. The flow velocity near the leakage point of the textile bag is larger, but the hydrostatic pressure is smaller, while the water pressure is large in the middle lower part of each textile bag due to its own water-blocking effect.

It can be seen from Figures 15(c) and 15(d) that the water pressure at the left and right ends of the textile bag is still related to the flow velocity at the leakage point. But in general, the water pressure on the water-resisting side of the textile bag is larger than that on the other side. When the total pressure difference formed is less than the friction resistance between the textile bag and the rock wall of the roadway, the textile bag will not slip. Due to the increasing influence of water flow, if the sum of water pressure misses the frictional resistance, the textile bag will slip or even fail. In addition, the longer the length of the textile bag, the more conducive to stability, and the shorter the textile bag, the more prone to "capsizing."

\subsubsection{Shape and Flow Field Change Rule of Textile Bag under} Different Water Pressure. Figure 16 shows the influence of flow field under different water pressure on the deformation of textile bag. The effect of different water pressure and flow field on the textile bag is summarized. Before there is no obvious slip between the textile bag and the surrounding rock wall, the deformation morphology of the textile bag is similar. The water leakage point is easy to form between the textile bag and the top of surrounding rock and the surrounding rock corner. Especially, the textile bag itself is a material with high softness, so it is difficult to ensure that the grouting slurry in the textile bag makes the textile bag and the top of the surrounding rock close together. In addition, the length 

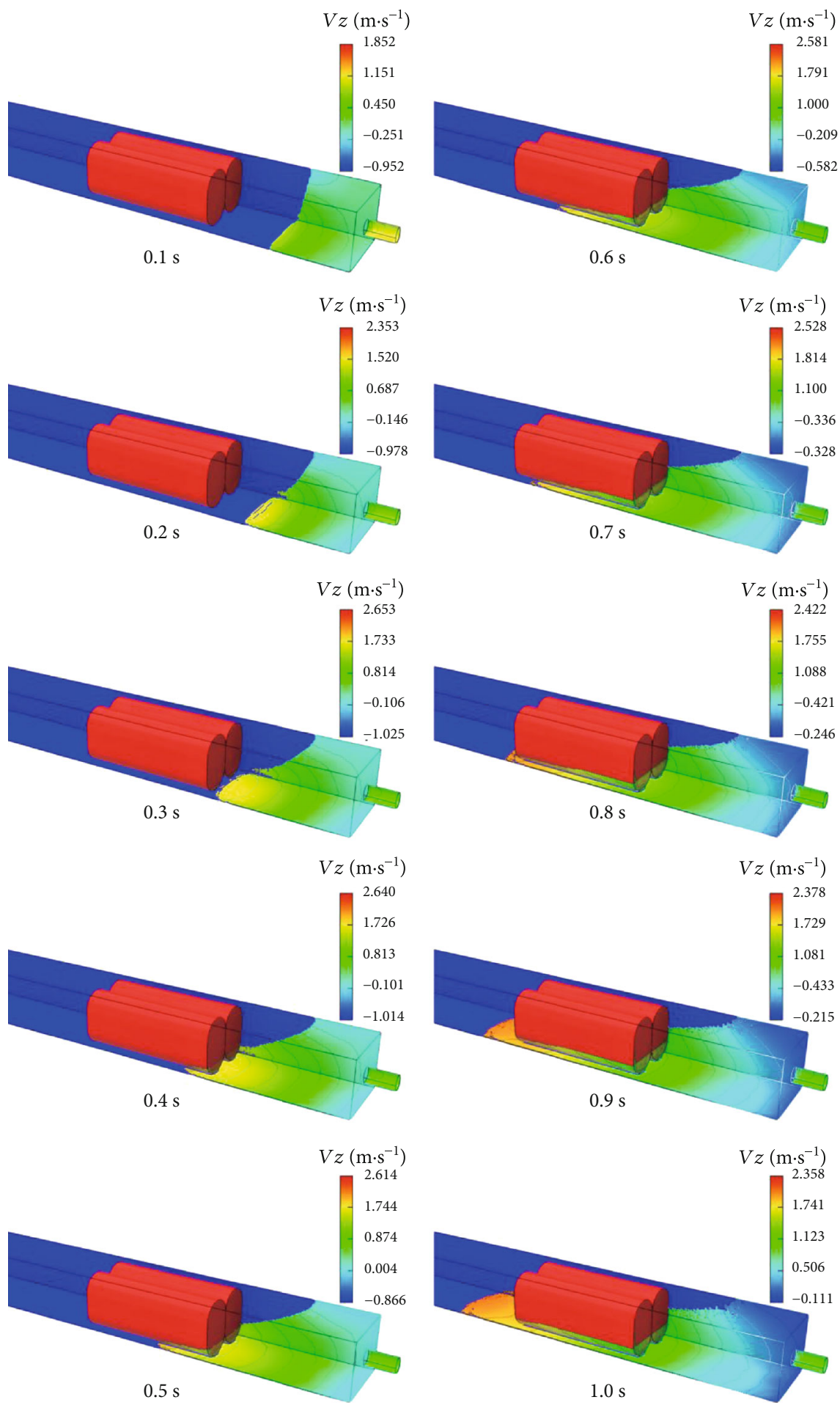

Figure 17: Influence of water flow fields at different times on the deformation of textile bag.

of the textile bag should be kept as long as possible under the convenient conditions to avoid overturning.

\subsubsection{Morphology Change Rule of Textile Bag under Different} Flow Fields. The water flow flows from $5 \mathrm{~m}$ away from the roadway to the opening of the roadway, and the water inlet of the roadway provides a flow velocity of $1 \mathrm{~m} / \mathrm{s}$. As can be seen from Figure 17, with the passage of time, the maximum water inrush velocity (V0.1s) in the roadway increases to $1.852 \mathrm{~m} / \mathrm{s}$ from $0.1 \mathrm{~s}$. At $0.3 \mathrm{~s}$, the maximum velocity (V0.3 s) in roadway increased to $2.653 \mathrm{~m} / \mathrm{s}$. From $0.35 \mathrm{~s}$, the water flows through the textile bag. At this time, the water is blocked and can only passes through the gap between the textile bag and the gap between the textile bag and the tunnel. But the initial flow velocity was only $1 \mathrm{~m} / \mathrm{s}$, so the flow velocity did not change much. At $0.5 \mathrm{~s}$, the maximum flow velocity 


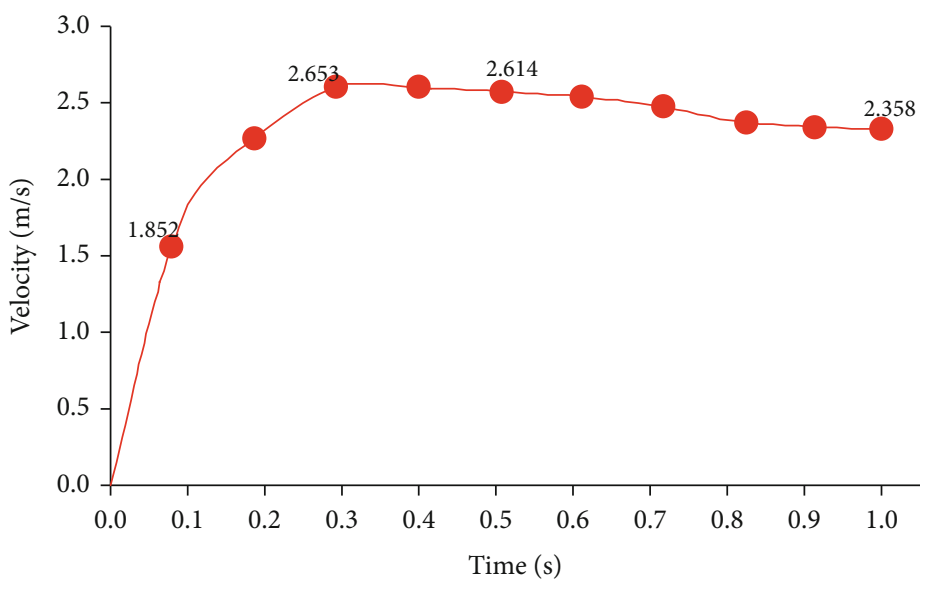

FIGURE 18: Relationship between maximum water flow velocity and time.

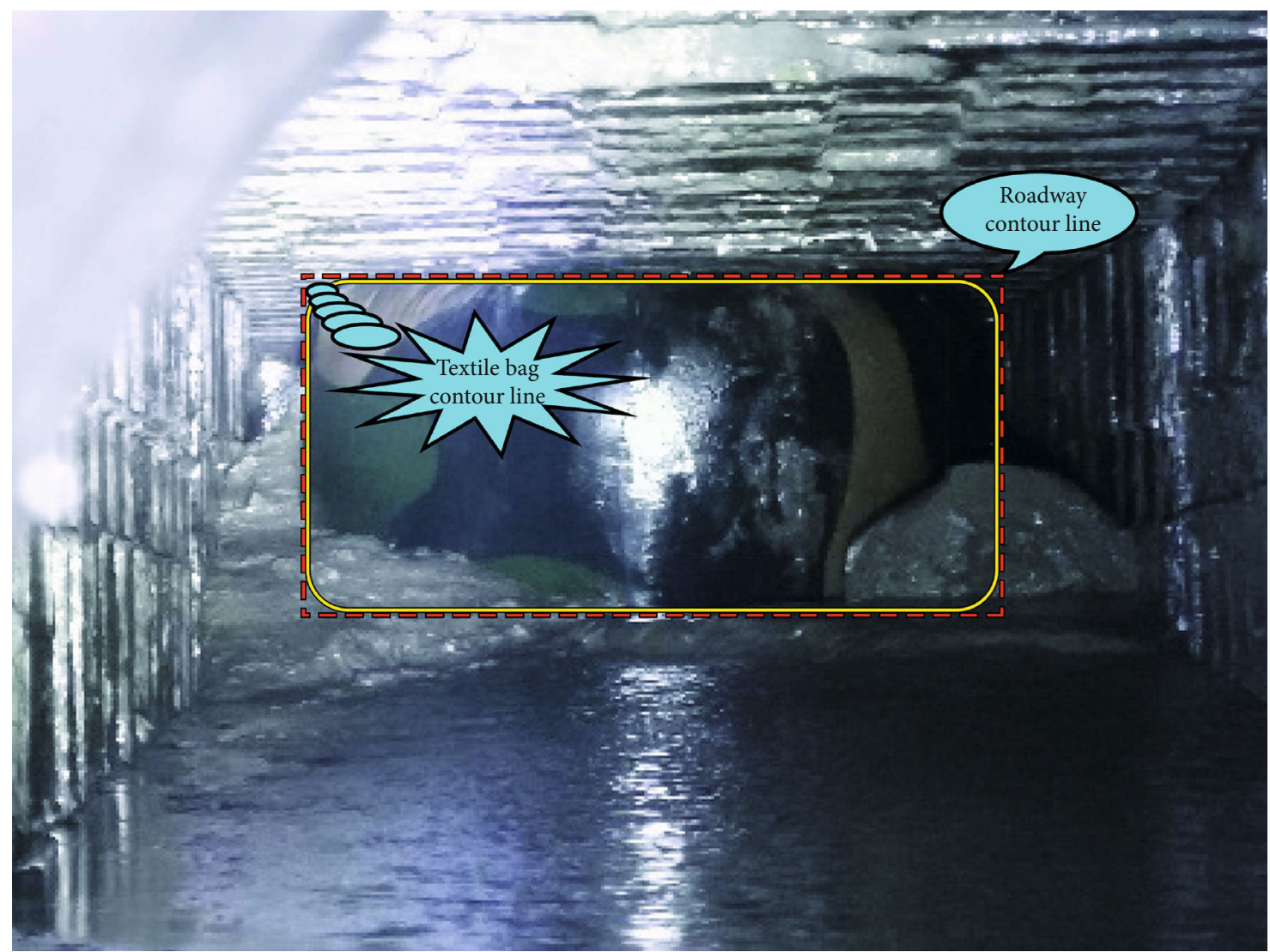

FiguRE 19: Effect of the textile bag of Yubujie on the treatment of moving water.

in the tunnel was only $2.614 \mathrm{~m} / \mathrm{s}$. When the water flow passes through the textile bag, and the water flow at the water inlet is small, the water supply is insufficient. When the tunnel water flow extension time reaches $1.0 \mathrm{~s}$, the maximum flow velocity drops to $2.358 \mathrm{~m} / \mathrm{s}$. At this time, the water in the water inlet end of the tunnel is blocked at one end by the textile bag, which plays a role in water resistance and slowing down the flow velocity. Figure 18 shows the relationship between the maximum flow velocity and time in the tunnel.

\section{Field Application}

Water disaster rescue project of Yubujie Coal Mine, Yulin, Shaanxi Province. The water pressure is $0.7 \mathrm{MPa}$, the continuous water surge is $1200 \mathrm{~m}^{3} / \mathrm{h}$, and the maximum water surge is $4000 \mathrm{~m}^{3} / \mathrm{h}$. 15 large size and 9 small size textile bags were used to block the tunnel through the water, which was successful at one time. The time was only 18 days, the drilling footage totaled $483 \mathrm{~m}$, and the grouting volume is $850 \mathrm{~m}^{3}$. 
TABLE 1: Comparison table between conventional grouting and grouting with textile bag control.

\begin{tabular}{lcccc}
\hline Plan & $\begin{array}{c}\text { Construction } \\
\text { period/d }\end{array}$ & $\begin{array}{c}\text { Grouting } \\
\text { quantity/m }\end{array}$ & $\begin{array}{c}\text { Project cost/ten thousand } \\
\text { yuan }\end{array}$ & $\begin{array}{c}\text { Cost of mine recovery/ten thousand } \\
\text { yuan }\end{array}$ \\
\hline $\begin{array}{l}\text { Conventional grouting } \\
\begin{array}{l}\text { Textile bag controls } \\
\text { grouting }\end{array}\end{array}$ & 150 & 850 & 600 & 3000 \\
\hline
\end{tabular}

Then, a trial drainage test was carried out, through the analysis of the test data, the water at the water inrush point was all blocked up, and the plugging rate was $100 \%$. After field exploration, the length of the blocked and consolidated body of the roadway is less than $50 \mathrm{~m}$. No secondary water inrush or abnormal situation occurs in the subsequent production blocked section.

\section{Field Verification}

According to theoretical analysis, the actual water pressure in the field is less than the ultimate hydraulic stress of the textile bag. That is, the textile bag can effectively control the actual water inrush on site within the limit of antihydraulic stress. According to the simulation results of the change of water pressure at the edge of the textile bag, it can be found that although the bag does not slip, there is a large head difference at both ends. It indicates that the grouting controlled by the textile bag cannot completely reduce the dynamic water flow. The over-water section must be further reduced through the supplementary grouting outside the bag in the later stage, so as to realize the rapid sealing of the dynamic water. As shown in Figure 19, it can be found from field application that the textile bag is not in complete contact with the roadway in the process of water blocking. Although the over-water section has been greatly reduced, there are still obvious residual over-water sections on both sides. This further explains the reason of the head difference between the two ends of the textile bag in the numerical simulation and confirms the key of the supplementary grouting in the later stage.

The results of field application show that the conclusions obtained by theoretical analysis and numerical simulation meet the design requirements. So the numerical simulation of water resistance mechanism of textile bag in the water passage is reasonable and feasible.

\section{Comparison with Conventional Grouting}

Through the field verification, compared with the conventional grouting scheme, the textile bag control grouting technology has a great advantage in the sealing of the moving water channel. See Table 1 for a detailed comparison.

It can be seen that, compared with the conventional grouting technology, the textile bag control grouting technology can significantly shorten the construction time, save a lot of grouting volume, and greatly reduce the cost of the engineering and recovery mining.

\section{Conclusions}

(1) A new flexible textile bag is presented, which can prevent a large amount of loss of aggregate due to dynamic water impact during grouting. Solve the uncontrollability of traditional dynamic water grouting technology to grouting aggregate

(2) The mechanical model of textile bag subjected to hydrodynamic action is established. The water plugging mechanism of textile bag is theoretically analyzed. The parameters of the bag are given, and the ultimate resistance to hydraulic stress of the textile bag is calculated. And the stress curve of textile bag subjected to hydraulic change is given, which provides a reference for numerical simulation and field application

(3) Based on the numerical simulation analysis of the water barrier effect, force, and flow field distribution of the textile bag, the accuracy of the conclusions obtained from the theoretical analysis is verified. By observing the changes of the water pressure field at the water inlet and outlet of the textile bag in the simulation process, whether the textile bag is effective for the treatment of dynamic water can be accurately judged. On the other hand, numerical simulation can also observe the stability and deformation of the textile bag before and after the dynamic water load, so as to ensure the reliability of the textile bag in the actual water plugging process

(4) Based on the field verification, the textile bag barrier technology of the water passage can quickly and effectively block the large water passage with moving water. Compared with the traditional grouting technology, it has significant advantages in terms of time limit, quantity of works, reliability, and cost. The successful application of this technology is of great significance to improve the technical level of mine rescue engineering in China, the chances of survival for those trapped, and the reliability of the project and shorten the rescue time of water disaster. In the future, mine water disaster rescue and control project has a broad application prospect

\section{Data Availability}

Some or all data, models, or code generated or used during the study are available from the corresponding author by request. 


\section{Conflicts of Interest}

The authors declare that there is no conflict of interest regarding the publication of this paper.

\section{Acknowledgments}

This study is funded by the Key Project of Shaanxi Provincial Key Laboratory of Coal Mine Water Disaster Prevention and Control Technology (2020SKZD02), the Open Projects of Key Laboratory of Coal Resources Exploration and Comprehensive Utilization, Ministry of Land and Resources (KF2020-5), the National Natural Science Foundation of China (Nos. 41402265 and 51874229), and the Natural Science Foundation of Shaanxi Province (2020JZ-52). The authors are grateful for financial assistance provided by the numerical simulation experiment platform provided by Xi'an University of Science and Technology, the background information and basic data provided by Xi'an Research Institute of China Coal Technology \& Engineering Group Corp, and the ideas and technical support of paper simulation experiment provided by Professor Mingcheng Zhu.

\section{References}

[1] J. Wu, "Progress, problems and prospects of prevention and control technology of mine water and reutilization in China," Journal of China Coal Society, vol. 39, no. 5, pp. 795-805, 2014.

[2] L. Mou, S. N. Dong, W. F. Zhou, W. Wang, A. Li, and Z. Shi, "Data analysis and key parameters of typical water hazard control engineering in coal mines of China," Mine Water and the Environment, vol. 39, no. 2, pp. 331-344, 2020.

[3] C. Y. Liu, J. X. Yang, and F. F. Wu, "A proposed method of coal pillar design, goaf filling, and grouting of steeply inclined coal seams under water-filled strata," Mine Water and the Environment, vol. 34, no. 1, pp. 87-94, 2015.

[4] Z. B. Yang and S. N. Dong, "Key technology of water inrush disaster control under hydrodynamic large channel condition," Coal Science and Technology, vol. 46, no. 4, pp. 110-116, 2018.

[5] C. Domingue, J. M. Lemieux, M. Grenon et al., "Numerical evaluation of grouting scenarios for reducing water inflows from major faults in underground excavations," Mine Water and the Environment, vol. 38, no. 3, pp. 497-506, 2019.

[6] S. Q. Liu, Y. Fei, Y. C. Xu, L. Huang, and W. Y. Guo, "Full-floor grouting reinforcement for working faces with large mining heights and high water pressure: a case study in China," Mine Water and the Environment, vol. 39, no. 2, pp. 268-279, 2020.

[7] G. L. Zhang, S. C. Yuan, W. H. Sui, and Z. W. Qian, "Experimental investigation of the pressure and water pressure responses of an inclined shaft wall during grouting," Mine Water and the Environment, vol. 39, no. 2, pp. 256-267, 2020.

[8] Z. B. Yang and S. N. Dong, "Study on quantitative evaluation of grouting effect by water pressure test," Journal of China Coal Society, vol. 43, no. 7, pp. 2021-2028, 2018.

[9] M. C. Zhu, "Application of controlled borehole grouting technology in large water channel plugging," Coal Geology of China, vol. 27, no. 5, pp. 46-49, 2015.

[10] M. C. Zhu, "Key technology and equipment of boreholecontrolled grouting for highly effective plugging large channel of water inrush," Coal Geology \& Exploration, vol. 43, no. 4, pp. 55-58, 2015.
[11] P. Bukowski, "Water hazard assessment in active shafts in upper Silesian Coal Basin mines," Mine Water and the Environment, vol. 24, no. 4, pp. 302-311, 2011.

[12] P. Fu, L. W. Huang, and Z. Q. Xing, "Development and experimental research of a low-thermal asphalt material for grouting leakage blocking," High Temperature Materials and Processes, vol. 39, no. 1, pp. 433-446, 2020.

[13] Y. J. Zhang, S. G. Wang, J. Wang et al., "A targeted grouting and water blocking method based on hydrological tracer testing and its engineering applications," Water, vol. 11, no. 5, article 1000, 2019.

[14] J. H. Zhao, L. Bo, C. Juntao, and J. Ning, "Mechanism of seepage-stress fault water inrush and grouting seal," Arabian Journal of Geosciences, vol. 13, no. 11, article 404, 2020.

[15] J. H. Hu, Q. F. Ren, S. W. Ma et al., "Macroscopic and microscopic trans-scale characteristics of pore structure of mine grouting materials," Transactions of Nonferrous Metals Society of China, vol. 29, no. 5, pp. 1067-1081, 2019.

[16] G. Fang, X. Y. Liang, H. Huang, Y. C. Xia, D. W. Jin, and Y. Liu, "Water-rich mechanism of coal seam and grouting and blocking water technology in Balasu mine feild," Journal of China Coal Society, vol. 44, no. 8, pp. 2470-2483, 2019.

[17] H. Y. Li, Y. C. Zhang, J. Wu, X. Zhang, L. Zhang, and Z. Li, "Grouting sealing mechanism of water gushing in karst pipelines and engineering application," Construction and Building Materials, vol. 254, article 119250, 2020.

[18] B. H. Xu, S. L. Ding, and F. Q. Bai, "Numerical simulation of grouting for stopping up water in water inrush accident of coal mine," Journal of China Coal Society, vol. 35, no. 10, pp. 1665$1669,2010$.

[19] S. C. Li, F. Xu, Q. Q. Zhang, W. M. Wang, H. L. Liu, and L. P. $\mathrm{Li}$, "Analysis and construction techniques for a water seal for underground mines subjected to water inrush," Mine Water and the Environment, vol. 35, no. 2, pp. 168-179, 2016.

[20] W. Qing-biao, Z. Qing-kai, S. Tang-sha et al., “The rheological test and application research of glass fiber cement slurry based on plugging mechanism of dynamic water grouting," Construction and Building Materials, vol. 189, pp. 119-130, 2018.

[21] S. Wang, R. H. Gong, Z. J. Li et al., "Water-blocking nanocomposite cement-based grouting materials," Applied Nanoscience, vol. 9, no. 7, pp. 1565-1578, 2019.

[22] L. Mou, S. N. Dong, S. T. Zheng, A. Li, and X. S. Ding, "Numerical simulation of water blocking wall construction based on CFD-DEM coupling method," Chinese Journal of Geotechnical Engineering, pp. 1-11, 2020. 